\title{
Autonomic cardiovascular reflex control of hemodynamics during exercise in heart failure with reduced ejection fraction and the effects of exercise training
}

\author{
Natasha G. Boyes ${ }^{1}$, Darcy D. Marciniuk ${ }^{2}$, Haissam Haddad ${ }^{2}$, Corey R. Tomczak ${ }^{1, *}$ \\ ${ }^{1}$ College of Kinesiology, University of Saskatchewan, Saskatoon, SK S7N 5B2, Canada \\ ${ }^{2}$ College of Medicine, University of Saskatchewan, Saskatoon, SK S7N 5B2, Canada \\ *Correspondence: corey.tomczak@usask.ca (Corey R. Tomczak) \\ Academic Editors: Kazuhiro P. Izawa, Peter H. Brubaker and Giuseppe Santarpino \\ Submitted: 29 October 2021 Revised: 20 December 2021 Accepted: 27 December 2021 Published: 21 February 2022
}

\begin{abstract}
Heart failure with reduced ejection fraction is associated with increased exercise intolerance, morbidity, and mortality. Importantly, exercise intolerance in heart failure with reduced ejection fraction is a key factor limiting patient quality of life and survival. Exercise intolerance in heart failure with reduced ejection fraction stems from a multi-organ failure to maintain homeostasis at rest and during exercise, including the heart, skeletal muscle, and autonomic nervous system, lending itself to a system constantly trying to "catch-up". Hemodynamic control during exercise is regulated primarily by the autonomic nervous system, whose operation, in turn, is partly regulated via reflexive information from exercise-stimulated receptors throughout the body (e.g., arterial baroreflex, central and peripheral chemoreceptors, and the muscle metabo- and mechanoreflexes). Persons with heart failure with reduced ejection fraction exhibit malfunctioning autonomic reflexes, which lead to exaggerated sympathoexcitation and attenuated parasympathetic tone. Chronic elevation of sympathetic activity is associated with increased morbidity and mortality. In this review, we provide an overview of how each main exercise-related autonomic reflex is changed in heart failure with reduced ejection fraction, and the role of exercise training in attenuating or reversing the counterproductive changes.
\end{abstract}

Keywords: sympathoexcitation; sympathetic nerve activity; metaboreflex; mechanoreflex; chemoreflex; arterial baroreflex; cardiac rehabilitation; HFrEF

\section{Introduction}

Chronic heart failure (HF) is a complex clinical syndrome [1] that 26 million people live with worldwide [2]. $\mathrm{HF}$ is characterized by severe exercise intolerance (i.e., low peak oxygen uptake $\left.\left(\mathrm{VO}_{2}\right)\right)$ [1,3-9], which limits daily activities, reduce quality of life [6], and increase the risk of adverse events in persons living with HF with reduced ejection fraction (HFrEF; EF $\leq 40 \%$ ) [7,8]. Patients with HFrEF classically have impaired cardiac output control and increased sympathetic outflow to muscle, vasculature, and the renal system at rest [10-15] and in response to exercise [16-19]. While sympathoexcitation increases in HFrEF, parasympathetic tone decreases, maintaining the patient in a sympatho-excited state even at rest. Thus, the HFrEF syndrome entails both myocardial and autonomic dysfunction [20], with the latter factor being the focus of this review.

The autonomic nervous system regulates cardiovascular and hemodynamic adjustments to changes in energy demand (e.g., exercise) and in times of stress. Here we will discuss the pathways and mechanisms by which the autonomic nervous system controls our hemodynamic responses to exercise, including the exercise pressor reflex (muscle metaboreflex and muscle mechanoreflex), the arterial baroreflex, and the chemoreflexes (central and peripheral) in the situation of HFrEF, i.e., autonomic dysfunction.

\section{Cardiovascular reflex physiology}

\subsection{Brief overview of the autonomic nervous system}

The autonomic nervous system has two primary branches: (1) the parasympathetic; and (2) the sympathetic nervous systems [21,22]. The balance between parasympathetic and sympathetic nerve activity modulates cardiovascular homeostasis and the response to exercise [21,23]. For example, at dynamic exercise onset, parasympathetic withdrawal causes a nearly instantaneous increase in heart rate. Conversely, increased sympathetic activation at exercise onset causes a gradual rise in heart rate. The dominant controller of heart rate thus shifts from parasympathetic actvity at rest (i.e., high activity) and during initial exercise onset (i.e., withdrawal) to sympathetic activity ("sympathoexcitation") during sustained exercise[23,24]

\subsection{Autonomic dysfunction in HFrEF}

Exaggerated sympathoexcitation in HFrEF may play a large role in disease progression [25] and is a marker of prognosis and survival [20,26]. At the onset of left ventricular systolic dysfunction, the balance between parasympathetic and sympathetic nerve activity shifts in response to: (a) an increase in left ventricular end-diastolic pressure; or (b) a decrease in stroke volume [20,26-28]. This shift in balance favours sympathoexcitation to temporar- 
ily re-establish hemodynamic equilibrium [21]. As HFrEF advances, parasympathetic outflow progressively wanes while sympathetic outflow increases [29], independent of HFrEF etiology [30,31]. Concurrently, renin-angiotensinaldosterone system activity increases [30,31]. These autonomic and neurohormonal responses may initially be "adaptive" to maintain cardiac function [21,30], but may subsequently and progressively become maladaptive and worsen HFrEF severity.

Autonomic dysfunction in HFrEF combines cardiac, ventilatory, neurohormonal, and vascular factors [6,28,30, 32] that are also related to poor prognosis [33] and increased mortality [20,34]. Cardiac factors may include decreased tonic and reflex vagal heart rate modulation, increased resting heart rate [34,35], chronotropic incompetence [36], and decreased heart rate variability [9,36-38]. Elevated resting minute ventilation [12] and ventilation-to-perfusion mismatch are also consistently found in $\mathrm{HFrEF}[6,33,39$, 40]. Neurohormonal changes in HFrEF include increased venous plasma norepinephrine, cardiac and renal norepinephrine spillover, cardiac norepinephrine stores, and plasma brain natriuretic peptides $[6,41]$. Increased renal sympathetic nerve activity reduces renal blood flow, which may in turn exacerbate the renin-angiotensin-aldosterone system [42]. Finally, increased resting muscle sympathetic nerve activity (MSNA) burst frequency in HFrEF [9-14] elicits tonic vasoconstriction and increased peripheral resistance at rest. Exaggerated sympathoexcitation in $\mathrm{HFrEF}$ is most common with severe exercise intolerance [15,19] or ischemic heart disease [9].

Contrary to initial conceptual models that emphasized a generalized, non-selective increase in sympathetic nerve activity to all vasculature in response to left ventricular systolic dysfunction [27], evidence suggests a selective alteration in autonomic cardiovascular changes in the early stages of HFrEF progression (e.g., increased cardiac norepinephrine spillover versus no change in total or renal norepinephrine spillover) [28]. Autonomic dysfunction in HFrEF may be examined as the exaggeration or blunting of cardiovascular regulating autonomic reflexes in response to exercise: the exercise pressor reflex, the arterial baroreflex, and the central and peripheral chemoreflexes [21,22] (Fig. 1, Ref. [21]). The current review is focused on extracardiac reflexes, therefore, the cardiopulmonary baroreflex and cardiac chemoreflex are not discussed herein. We refer the reader to this review for further detail [43].

\section{Exercise pressor reflex in $\mathrm{HFrEF}$}

Curiously, muscle reflex physiology may play a large role in HFrEF exercise pathophysiology. First described by Alam and Smirk in 1937, the exercise pressor reflex is stimulated by skeletal muscle contraction to generate an increase in mean arterial pressure and ventilation during exercise in healthy humans $[44,45]$. The exercise pressor reflex is stimulated via group III and IV muscle affer- ents and encompasses two separate reflexes: (1) the muscle mechanoreflex (mainly group III afferents); and (2) the muscle metaboreflex (mainly group IV afferents). Their purpose is to increase sympathoexcitation during exercise to maintain the balance between cardiac output and peripheral $\mathrm{O}_{2}$ supply, thereby maintaining arterial pressure and preserving cerebral and cardiac $\mathrm{O}_{2}$ supply during exercise [46]. Indeed, an abolished exercise pressor reflex impairs the ability to increase mean arterial pressure during exercise [47]. The exercise pressor reflex is consistently exaggerated in patients with HFrEF [3,4,19,45,46,48-50].

The exercise pressor reflex is thought to be the "neural link" between peripheral muscle abnormalities and exaggerated hemodynamic responses to exercise in HFrEF [51]. When group III and IV muscle afferents were blocked via lumbar intrathecal fentanyl administration during knee extension exercise in patients with HFrEF, there was attenuated sympathetic outflow (i.e., lower total norepinephrine spillover) and lower exercise cardiac output, but there was also increased femoral blood flow and vascular conductance and less exercise fatigue [52]. Thus, the exercise pressor reflex may modulate central hemodynamic control and elicit exaggerated sympathoexcitation that impairs femoral blood flow during exercise in HFrEF but not in controls [52]. The exaggerated exercise pressor response may be related to impaired muscle quality and function (e.g., muscle atrophy, altered enzyme concentrations, lower mitochondrial density, rapid exercise high energy phosphate decline [53-55]), impaired muscle $\mathrm{O}_{2}$ delivery-to-utilization matching and/or reduced muscle $\mathrm{O}_{2}$ diffusional conductance during exercise in patients with HFrEF [5,56,57]. Conversely, another report shows an exaggerated exercise pressor response not attributable to muscle $\mathrm{O}_{2}$ extraction in $\mathrm{HFrEF}$, although a normal response was related to muscle $\mathrm{O}_{2}$ extraction in controls [49]. Some evidence suggests ATP and lactic acid may stimulate and sensitize group III and IV muscle afferents and thus help exaggerate sympathoexcitation in HFrEF [46]. Clinically, exaggerated sympathoexcitation from an abnormal exercise pressor response may be related to exercise intolerance in HFrEF [52], with potentially different contributions from the mechanoreflex and the metaboreflex.

\subsection{Muscle mechanoreflex in HFrEF}

The muscle mechanoreflex may independently contribute to HFrEF pathophysiology. Deformation of the skeletal muscle mechanoreceptors increases the muscle afferent signalling rate to the central nervous system [46]. Mechanoreceptors rapidly adjust their firing rate to changes in muscle tension consistency and respond earlier and faster than metaboreceptors [47]. The mechanoreflex elicits an increase in sympathoexcitation that increases arterial and renal vasoconstriction [58], and that debatably/negligibly increases ventilation $[3,4,47]$. Thus, muscle contraction indirectly increases perfusion pressure and $\mathrm{O}_{2}$ delivery to ac- 


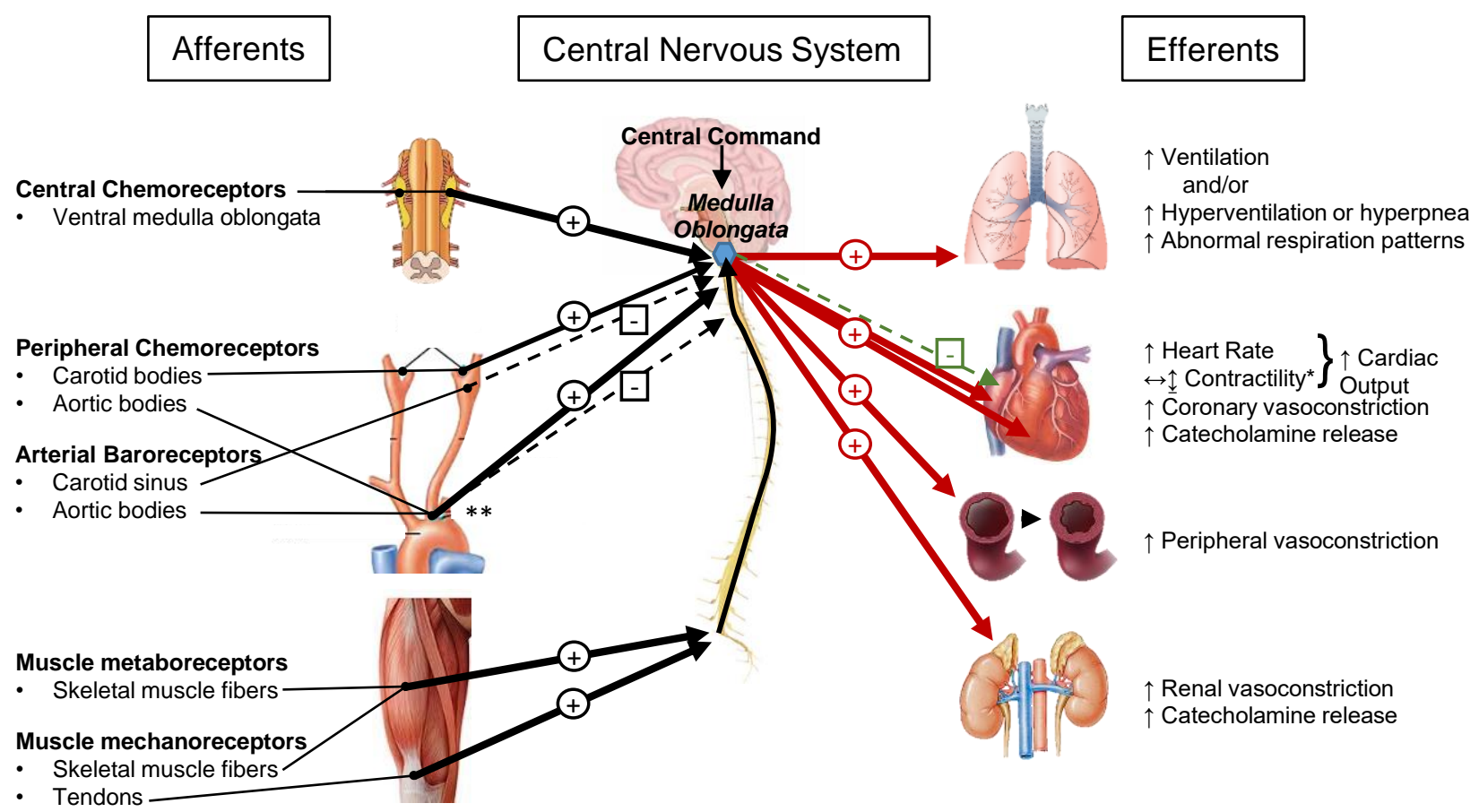

Fig. 1. Integration of exercise-related, cardiovascular autonomic reflexes in HFrEF. Afferent feedback is collected and integrated at the medulla oblongata of the brain stem (blue hexagon), where from efferent signals are sent to various organs in response to the integration of the afferent and central information. Excitatory (+) and inhibitory (-) stimuli are shown for afferent feedback (black arrows), efferent sympathetic nerve activity (red arrows) and efferent parasympathetic nerve activity (green arrows). Exaggerated stimuli due to HFrEF are indicated as thick arrows, while blunted stimuli due to HFrEF are indicated as dashed thin arrows. *Note: the effects of sympathoexcitation on cardiac contractility in HFrEF are generally to increase contractility, but some research suggests stroke volume remains the same or decreases during the activation of the metaboreflex in HFrEF. **Note: the aortic bodies contain both baroreceptors and chemoreceptors, which emit contrasting afferent signals. The baroreflex stimulus is inhibitory and is blunted in HFrEF; the chemoreflex stimulus is excitatory and is exaggerated in HFrEF. Figure concept and representation of afferent and efferent pathways was inspired by figure 4 in reference [21].

tive tissues and prevents peripheral blood flow from surpassing cardiac output during exercise $[46,47]$. Studies isolating the mechanoreflex from both the metaboreflex and central command are scarce [48] and may use passive muscle stretch, electrically stimulated involuntary muscle contractions, or low-intensity handgrip exercise (this includes central command).

Renal vasoconstriction during exercise is exaggerated during isolated mechanoreflex but not metaboreflex activation in HFrEF [58]. In contrast, the mechanoreflex has little effect on the exercise ventilatory response in both HFrEF and health, while the metaboreflex has a large regulatory role in ventilation modulation during exercise $[3,4]$. In rodents with dilated cardiomyopathy (coronary ligation), the exercise pressor response and isolated mechanoreflex activity (i.e., mean arterial pressure and heart rate responses) progressively increased as left ventricular function decreased over a 10-week period [59]. Thus, an exaggerated mechanoreflex response in HFrEF may be systolic function dependent [59]. MSNA increased similarly during normal exercise in HFrEF compared to controls, both with dichloroacetate (which reduces lactic acid production) or saline (placebo) transfusion, but increased earlier during exercise in HFrEF compared to controls during placebo [50]. Further, mechanoreflex isolation via passive arm stretch caused an exaggerated early and sustained elevation of MSNA in HFrEF compared to no effect in controls [50]. Thus, there may be a prominent role for increased mechanosensitivity in the exaggerated sympathoexcitation during exercise in patients with HFrEF [50]. Additionally, the findings suggest muscle acidity does not affect mechanoreceptor sensitization in patients with HFrEF [50], which contrasts other reports [46]. In summary, the mechanoreflex may be exaggerated in HFrEF, such that renal vasoconstriction, mean arterial pressure, heart rate, and MSNA responses to exercise are elevated.

\subsection{Muscle metaboreflex in HFrEF}

The muscle metaboreflex independently contributes to exaggerated sympathoexcitation in $\operatorname{HFrEF}[3,4,19,47,60]$. 
The metaboreflex occurs when increased metabolite concentration (e.g., ATP [61], lactic acid, adenosine [10], phosphate, kinins, and cations $[47,62])$ stimulates skeletal muscle receptors, whose afferent firing rate increases to yield hemodynamic, ventilatory, and sympathetic changes [21]; these changes include increases in MSNA, peripheral vasoconstriction [47], mean arterial pressure, pulmonary vascular resistance [63], and ventilation or hyperpnea [47]. During exercise, the metaboreflex increases cardiac output via stroke volume in health [64] and potentially heart rate [65] depending on the state of exercise, recovery, or ischemia [47]. However, the presence of HFrEF alters these effects.

The metaboreflex is consistently elevated in patients with HFrEF $[21,66]$ such that MSNA during ischemic and nonischemic handgrip exercise is greater and occurs earlier [19]; exercise ventilation is amplified due to an exaggerated metaboreflex response $[3,66,67]$ in symptomatic but not in asymptomatic patients with HFrEF [68]; postexercise heart rate recovery is slower [60]; and arterial pressure is elevated during post-exercise circulatory occlusion $[60,64,67,69-71]$. While increased arterial pressure is primarily due to increased cardiac output in health, metaboreflex activation in HFrEF elicits negligible cardiac output changes and thus elevates mean arterial pressure via peripheral vasoconstriction and elevated systemic vascular resistance [63,64,69-71]. A dose-response relationship for this phenomenon was recently reported across three metaboreflex exercise intensities [72]. Cardiac output was limited during metaboreflex activation because of increased coronary vasoconstriction in dogs with HFrEF, but this has yet to be confirmed in humans with HFrEF [73]. Thus, the metaboreflex mechanisms in HFrEF may be related to the impaired ability to increase stroke volume during exercise [64,70,71].

In HFrEF, metaboreflex sensitivity and activity are negatively related to peak $\mathrm{VO}_{2}[19,67]$ and heart rate variability (indirect measure of cardiac autonomic regulation and associated with higher mortality [67,74]), and are positively related to the exercise ventilatory response [51,67], circulating catecholamine levels [67], and mortality risk score [68]. Further, metaboreflex activity is not related to ventricular function [67], and yet it increases as HFrEF severity worsens [51]. Metaboreflex exaggeration in HFrEF may be associated with increased peripheral, but not central, chemoreflex sensitivity and decreased arterial baroreflex regulation of heart rate, independent of left ventricular EF [67].

Some research suggests that HFrEF, perhaps only in its more severe form, attenuates [46] or has no effect on the metaboreflex [50]. Patients with mild HFrEF and controls have elevated MSNA and blood pressure during metaboreflex activation but not in those with severe HFrEF [75]. Further, one HFrEF group observed a decrease in MSNA from exercise to post-exercise ischemia while controls observed an increase [11]. The same group later published directly contrasting results in addition to earlier fatigue and greater accumulation of muscle metabolites in HFrEF, thus supporting the overall metaboreflex exaggeration in HFrEF [76]. Conflicting results on metaboreflex activity in HFrEF may result from different measured physiological indices (e.g., MSNA vs. ventilation vs. blood pressure) [77], exercise modes (e.g., rhythmic or isometric), muscle group (e.g., forearm or knee extensor), and/or HFrEF severity (e.g., muscle quality, muscle afferent sensitization or desensitization). For more on this, we refer the reader to the Wang et al. [77] and the give and take discussion between the blunted and exaggerated hypotheses. Taken together, we know muscle metaboreflex dysfunction in HFrEF alters exercise and post-exercise MSNA (mixed views on blunted vs. exaggerated responses [47]), and increases exercise and post-exercise blood pressure, vasoconstriction, and ventilation. Thus, dysfunctional metaboreflex may play a critical role in manifesting HFrEF exaggerated sympathoexcitation, early fatigue, and exercise intolerance.

\section{Arterial baroreflex in HFrEF}

The attenuated arterial baroreflex control of heart rate in patients with $\mathrm{HFrEF}[28,32,78-80]$ is associated with poor survival [81]. The arterial baroreceptors, located in the aortic arch and carotid sinuses, facilitate a negative feedback reflex that responds to stretch from a sudden increase in blood pressure by signalling afferents to the medulla oblongata. This will: (a) decrease sympathetic activity to the heart and vessels (i.e., lower heart rate, contractility, and vasoconstriction); and (b) increase parasympathetic activity to lower heart rate [22,32]. Baroreflex activation thus lowers blood pressure via cardiac output, peripheral resistance, and venous return; the opposite effects would occur with a drop in baroreceptor activity [32].

How arterial baroreflex function is altered in HFrEF is debated. Some propose that the baroreflex responds appropriately to detected decreases in stroke volume or diastolic pressure by increasing sympathoexcitation in HFrEF [21]. Others describe normal baroreflex circuits in HFrEF with, however, exaggeration of other sympatho-excitatory reflexes that may override baroreflex function, such as the exercise pressor and chemoreflexes [82]. Conversely, somewhat conflicting evidence suggests arterial baroreflex dysfunction: heightened baroreflex sensitivity (i.e., the response magnitude when the baroreflex effectively drives the sinus node) in HFrEF [83]; reduced baroreflex sensitivity in optimally-treated patients with HFrEF [84]; reduced baroreflex sensitivity being related to pulse wave velocity and not EF, suggesting that structural alterations of the arterial wall may modulate baroreflex function [84]; and depressed baroreflex effectiveness index (i.e., the number of times the baroreflex effectively drives the sinus node) in a sample with no abnormal baroreflex sensitivity in HFrEF [85]. The baroreflex effectiveness index may be a better measure in HFrEF as it accounts for non-baroreflex con- 
trol of heart rate, such as central command, ventilation, and neurohormonal factors, each of which may be abnormal in HFrEF [85]. Notwithstanding the preferred measure, a recent publication reported not only reduced baroreceptor sensitivity in patients with HFrEF, but a relationship between ejection fraction and baroreceptor sensitivity such that as ejection fraction declines, baroreceptor sensitivity declines [86]. Indeed, patients with HFpEF exhibited no such relationship nor any decline in baroreceptor sensitivity. Other functional relationships with baroreceptor sensitivity including MSNA, heart rate, and catecholamine levels [86]. Therefore, it may be surmised from the bulk of the literature that baroreflex dysfunction exists in those with HFrEF, however, the degree of dysfunction may be dependent upon the severity of the HFrEF state and level of neuroadrenergic activation.

Baroreflex modulation of heart rate, cardiac output, and blood pressure is depressed in HFrEF dogs at rest [8791], during mild and moderate exercise [92,93], and during metaboreflex activation [94], but without effect on the baroreflex modulation of vascular resistance at rest [91]. Thus, the ability of the baroreflex to buffer the metaboreflex is diminished in HFrEF dogs [93,94]. Further, baroreflex unloading via bilateral carotid occlusion during concurrent muscle metaboreflex activation in dogs with HFrEF causes vasoconstriction in all vascular beds, non-ischemic and ischemic active tissue alike, resulting in a surge in mean arterial pressure as a result of a great pressor response [95]. This heightened sympathetic outflow as a result of baroreflex unloading in HFrEF initiates a "vicious cycle" of vasoconstriction in active tissue, which enhances the muscle metaboreflex, which causes more vasoconstriction. The authors speculate that baroreflex dysfunction coupled with muscle metaboreflex exaggeration may be a feedback loop exacerbating exercise intolerance in patients with HFrEF [95]. The interaction between these dysfunctional reflex systems in HFrEF appears to play a leading role in HFrEF pathophysiology and exercise intolerance. However, this stream of evidence comes with validity limitations. Exercise heart rate dominantly controls cardiac output in healthy dogs, whereas exercise stroke volume modulates cardiac output in HFrEF dogs [93]. This directly opposes previous work in HFrEF dogs by the same group [71], and therefore should be further investigated in patients with HFrEF of various severity and etiology.

Baroreflex sensitivity is improved after exercise training in HFrEF [30] and after simulating exercise training with electrical stimulation of the peroneal and tibial nerves [96]. Baroreflex activation therapy (carotid sinus stimulation) safely improved exercise capacity, functional class, and quality of life, and reduced NT-proBNP levels in patients with HFrEF already optimally treated with guideline therapy [97]. Vagal nerve stimulation therapy in NYHA class II-III HFrEF patients yielded similar but inconsistent findings to baroreflex activation therapy, with no apparent benefit to survival or heart function [98-100]. Recently, a series published in the Lancet reviewed baroreceptor stimulation as a non-pharmacological treatment of autonomic dysfunction in heart failure, however, outcomes were minimal, showing improved exercise capacity but no improvement in cardiac function, and trial control patient groups were not included [101], lending themselves to low-impact findings and implications. To summarize, baroreflex control of heart rate is impaired in HFrEF, however, the mechanisms may be outside the baroreceptors themselves [21,82] or related to arterial stiffness [32,84]. Improved arterial baroreflex sensitivity impacts exercise tolerance and quality of life $[82,97]$ but not necessarily prognosis.

\section{Chemoreflex in HFrEF}

The chemoreflex may be exaggerated in patients with HFrEF, observed as abnormal ventilation at rest [102] and blunted vasodilation during exercise due to exaggerated MSNA [12]. The chemoreflex modulates homeostasis under conditions of hypercapnia, acidosis, or hypoxemia [32]. The chemoreflex has two levels: (1) the central chemoreflex; and (2) the peripheral chemoreflex. The chemoreceptors respond to hypoxemia and/or hypercapnia by stimulating increases in ventilation and sympathetic outflow, with the goal of increasing tissue perfusion, $\mathrm{O}_{2}$ delivery and utilization, and $\mathrm{CO}_{2}$ mobilization and expiration [32]. Interestingly, increased ventilation partially buffers sympathetic nerve activity via competition between pulmonary stretch afferents (not discussed here) and the chemoreflexes $[103,104]$; however, in patients with HFrEF, increased ventilation and exaggerated sympathoexcitation commonly coexist [13]. Conceptually, patients with HFrEF commonly have lower cardiac output and organ perfusion, which would increase glycolytic metabolism. Thus, elevated $\mathrm{CO}_{2}$ and $\mathrm{H}^{+}$levels and decreased $\mathrm{O}_{2}$ levels in the blood may exaggerate the chemoreflexes over time [32]. Further, patients with HFrEF exhibit blunted muscle vasodilation during both central and peripheral chemoreflex activation compared to controls, likely attributable to the greater increase in MSNA observed in the patients [12]. Both central and peripheral chemosensitivity may contribute to exercise hyperventilation in HFrEF [83], which may compensate hemodynamically by increasing cardiac output via heart rate in health and HFrEF [105].

\subsection{Central chemoreflex in HFrEF}

The central chemoreceptors are located adjacent to the respiratory centres in the medulla oblongata and detect blood $\mathrm{CO}_{2}$ and $\mathrm{pH}$ levels. When blood $\mathrm{CO}_{2}$ levels rise ("hypercapnia"), there is more $\mathrm{CO}_{2}$ in the interstitial space surrounding the central chemoreceptors, triggering afferent signals to the respiratory centres in the medulla oblongata. The respiratory centres respond by raising ventilation. Studies targeting the central chemoreflex activate the $\mathrm{CO}_{2}$-sensitive central chemoreceptors while simultane- 
ously deactivating the $\mathrm{O}_{2}$-sensitive peripheral chemoreceptors by breathing hyperoxic hypercapnic gas $\left(93 \% \mathrm{O}_{2}\right.$ and $7 \% \mathrm{CO}_{2}$ [83]). Patients with HFrEF have greater ventilation [13], heart rate [13], and MSNA [12,13] and decreased forearm blood flow [12] during resting hyperoxic hypercapnia compared to controls. Further, symptomatic patients have greater MSNA and ventilation and attenuated sympathoinhibition during hyperoxic hypercapnia compared to asymptomatic HFrEF patients [106]. These findings are clinically relevant as blood $\mathrm{CO}_{2}$ levels increase during exercise and/or sleep apnea, therefore, in patients with HFrEF, elevated blood $\mathrm{CO}_{2}$ levels exaggerate the central chemoreflex and exacerbate the already elevated sympathoexcitation. Clinically, hyperventilation is more prognostic than peak $\mathrm{VO}_{2}$ in $\mathrm{HFrEF}$ [83], although both are meaningful endpoints. Abnormal exercise hyperventilation in HFrEF is often due to high ventilation-to-perfusion mismatch and increased $\mathrm{VCO}_{2}$ due to greater bicarbonate buffering of lactic acid [107]. Even so, there is more data on the peripheral rather than central chemoreflex during exercise in HFrEF.

\subsection{Peripheral chemoreflex in HFrEF}

Exaggerated peripheral chemoreflex activity is common in HFrEF and may contribute to exaggerated sympathoexcitation, hyperventilation, breathing instability (e.g., Cheyne-Stokes) [102,108], and autonomic dysfunction in HFrEF [30]. The peripheral chemoreceptors ("glomus cells") in the carotid bodies and aortic arch detect blood $\mathrm{O}_{2}$ levels. When blood $\mathrm{O}_{2}$ levels fall, the chemoreceptors depolarize the glossopharyngeal and vagus nerves, signaling the medulla oblongata to increase ventilation [102], increase heart rate [103], and increase vasoconstriction to maintain perfusion pressure $[12,102]$. The peripheral chemoreflex is investigated using steady-state $\left(10 \% \mathrm{O}_{2}\right.$ and $90 \% \mathrm{~N}_{2}$ [12]) or transient (100\% $\mathrm{N}_{2}$ [109]) hypoxia. Titrating $\mathrm{CO}_{2}$ uptake maintains arterial isocapnia to minimize central chemoreflex activity [12].

Hypoxemia increases ventilation at rest and during exercise, and decreases the peak work rate but not peak $\mathrm{VO}_{2}$ in HFrEF [39], the latter suggesting greater work of breathing with hypoxia. Patients with HFrEF had greater MSNA and reduced forearm blood flow compared to controls during resting isocapnic hypoxia [12]. Carotid chemoreceptor inhibition via dopamine caused resting hindlimb vasodilation in HFrEF but not healthy dogs, while both groups experienced similar exercise vasodilation [110]. By adding alphaadrenergic blockade with phentolamine, carotid chemoreceptors accounted for roughly $1 / 3$ rd of the sympathetic tone during exercise in healthy dogs [110] while this additional blockade abolished exercise vasodilation in HFrEF dogs [110]. Notably, carotid body denervation in two healthy dogs abolished the exercise vasodilation [110]. Thus, peripheral chemoreflex sensitivity is exaggerated in HFrEF [102]. Indeed, animal models indicate that the transformation from normal, tonic chemoreceptor activity to HFrEF- characteristic chemoreceptor hyperactivity may occur in a matter of weeks [102].

The carotid chemoreflex interacts with the muscle metaboreflex to regulation minute ventilation in a breathing frequency dependent manner in patients with HFrEF, potentially contributing the exercise hyperventilation and exercise intolerance in HFrEF [111]. In other words, the activation of the muscle metaboreflex worsens the effects of the already hyperactive carotid chemoreflex in patients with HFrEF; as exercise stimulates both reflexes, this interaction may be a key player in functionally limiting exercise tolerance, which in turn is related to quality of life and mortality in HFrEF. The interaction between these situationally distant reflexes poses a therapeutic problem pharmacologically, however, exercise therapy (see section 1.6) may be used to address both reflexes individually and thus improve the nature of their interaction in patients with HFrEF.

Carotid body ablation, resection, or denervation have demonstrated improved autonomic function (reduced renal sympathetic nerve activity or MSNA, increased renal blood flow, increased heart rate variability, reduced peripheral chemosensitivity, increased baroreflex sensitivity) in animal HFrEF models [112-114]. A 2017 first-in-man study demonstrated that carotid body resection (4 patients unilateral resection, 6 patients bilateral resection) in HFrEF decreased both MSNA and peripheral chemosensitivity and improved exercise tolerance 1-month post-resection [115]. However, safety concerns arose in those with bilateral resection who trended lower of oxygen saturation at night [115]; carotid bodies stimulate protective reactions to hypoxia, therefore, further investigation balancing patient safety and clinical benefit is required prior to wider usage of carotid body resection or alteration. Although still debated, hemodynamic, neurohumoral, and local metabolic mechanisms underlying HFrEF pathophysiology may collectively progress peripheral chemoreceptor sensitization [102]. Despite the high $\mathrm{O}_{2}$ supply to peripheral chemoreceptors in health, it is speculated that relatively reduced $\mathrm{O}_{2}$ supply in HFrEF may play a role in peripheral chemoreceptor sensitization [102]. As previously mentioned, hyperventilation, sleep apneas, and Cheyne-Stokes respiration are common in patients with HFrEF and are secondary to peripheral chemoreflex exaggeration, not vice versa [102]. However, these ventilatory abnormalities may also exacerbate the mechanisms of chemoreflex exaggeration [102]. Oxidative stress may stimulate carotid chemoreceptor sensitization in HFrEF [32,102]. Chronic exposure to intermittent hypoxemia, as is common in HFrEF, sensitizes the carotid chemoreceptors to be more "excitable" to acute hypoxemia in HFrEF rats, likely due, in part, to greater carotid body oxidative stress [116]. Angiotensin II, a pro-oxidant, is chronically elevated in $\sim 45-50 \%$ of patients with severe HFrEF (NYHA class III-IV) despite ACE inhibitor treatment $[117,118]$ and is associated with poor prognosis in HFrEF [117]. The NADPH-angiotensin II-superoxide 
pathway may increase carotid body chemoreceptor sensitivity to hypoxemia in humans with HFrEF [119]. Finally, comorbidities common in HFrEF are also related to increased oxidative stress and may exacerbate carotid body sensitization [32]. Therefore, the role of oxidative stress remains an essential component of HFrEF pathophysiology. In summary, the peripheral chemoreflex is exaggerated in patients with HFrEF and contributes to abnormal ventilation.

\section{The role of exercise training on reflex control of cardiovascular hemodynamics}

Exercise training is a highly effective therapy that increases not only functional capacity, but enhances quality of life, resting heart rate, ventilatory efficiency, and ejection fraction, as well as reduces the incidence of major cardiovascular events, hospitalizations, and cardiac mortality [120-122] and thus shows promise as an effective therapy for autonomic dysfunction [42]. Further, exercise training reduced the rate of new-onset atrial arrhythmias, but not ventricular arrhythmias, in patients with HF. Indeed, lower peak $\mathrm{VO}_{2}$ scores were predictive of greater mortality risk and new-onset atrial arrhythmias in trained patients with HF [122]. This remains significant as the presence of atrial fibrillation is associated with lower pre-training peak $\mathrm{VO}_{2}$, greater hospitalization and mortality risk [123]. Arrhythmias are associated with cardiac related death in patients with HFrEF, and low ejection fraction, as such found in patients with HFrEF, remains the only consistent predictor of sudden cardiac death in patients with ischemic heart disease [124]. Thus, coupling exercise with the current anti-arrhythmitic therapies, such as cardiac resynchronization therapy, may further reduce arrhythmias and subsequent cardiac death. In the same vein, chronotropic incompetence, characterized by the inability to adequately increase heart rate in response to exercise, is mediated by sympathovagal balance and commonly found in patients with HFrEF [125]. Evidence indicates that exercise training may partially ameliorate chronotropic incompetence in patients with HFrEF [125]; it is therefore reasonable to infer that exercise training may be coupled with implantable device therapy to collectively improve sympathovagal balance, chronotropic incompetence, and outcomes. However, this has yet to be fully investigated.

A recent meta-analysis (study $n=16$ ) by Pearson and Smart [126] reported exercise training improved short-term heart rate variability (study $n=11 ; 2$ studies with HF with preserved ejection fraction), decreased MSNA (study $n=$ 6 ), and increased heart rate recovery at 1-min post-exercise (study $n=5$ ) in exercise-trained patients with HFrEF compared to non-exercise trained HFrEF controls. Several animal HFrEF models have reported decreased sympathetic activation or improved hemodynamic control following exercise training [113,127-132]. Exercise training in rat models of HFrEF increased parasympathetic tone and intrinsic heart rate compared to untrained rats with HFrEF, such that post-training values achieved no difference with healthy sham rats [133]. Further, normalized parasympathetic activity was related to training-induced preservation of preganglionc vagal neurons [133]. Early evidence in patients with HFrEF exhibited a shift from sympathetic to parasympathetic dominance after 5-8 weeks of exercise training [134-136]. Similarly, 9 months of exercise training shifted the sympathovagal balance toward a greater parasympathetic tone in patients with HFrEF, but this effect required a long time course as it was not seen at 3 months [137]. Improved sympathovagal balance, as measured by a decrease in the ratio of low frequency to high frequency with power spectral heart rate analysis, was inversely correlatd with increased peak $\mathrm{VO}_{2}$ as a result of exercise training in patients with HFrEF [138]. Improvement in both time and frequency domains of heart rate variability [30,126,134,137,139-141] and reduced sympathetic nerve activity following exercise training in patients with HFrEF has been well documented $[43,142]$. This section will therefore focus on individual autonomic reflex-specific improvements following exercise training in HFrEF for a mechanistic approach (Fig. 2).

\subsection{Role of exercise programming on autonomic reflex function in $\mathrm{HFrEF}$}

It is imperative to consider that improved exercise capacity, cardiac function, and/or skeletal muscle function does not equal improved autonomic function. Similar to how exercise regime (moderate intensity continuous training, high intensity interval training, resistance training, etc.) yields different health and clinical benefits improve autonomic function, although the majority include some form of aerobic training. Low intensity cardiac rehabilitation in patients with HFrEF [143], whether or not the exercise regime improves autonomic function in HFrEF may depend greatly on the mode, duration, and intensity of exercise [30]. Nonetheless, it appears that a wide variety of regimes restored autonomic tone and reactivity to sympathetic and parasympathetic stimuli in patients with HFrEF [137]. An aerobic, resistance-band training study targeting each muscle group one at a time lowered circulating catecholamine levels at rest and during exercise in HFrEF patients [144]. Combined interval and resistance training had statistically similar effects on respiratory drive compared to interval training alone in patients with $\mathrm{HFrEF}$, but data indicated that combined training may have improved resting and exercise breathing pattern indices and $\mathrm{P}_{E T} \mathrm{CO}_{2}$ more than intervals alone [145]. Inspiratory muscle training has produced benefits to exercise tolerance and potentially autonomic function in patients with HFrEF [146]. Clearly, exercise training program parameters (frequency, intensity, type, and time) are highly varied among autonomic studies in patients with HFrEF. Therefore, studies explicitly evaluating autonomic measures and mechanisms are required in and above clinical outcomes. 


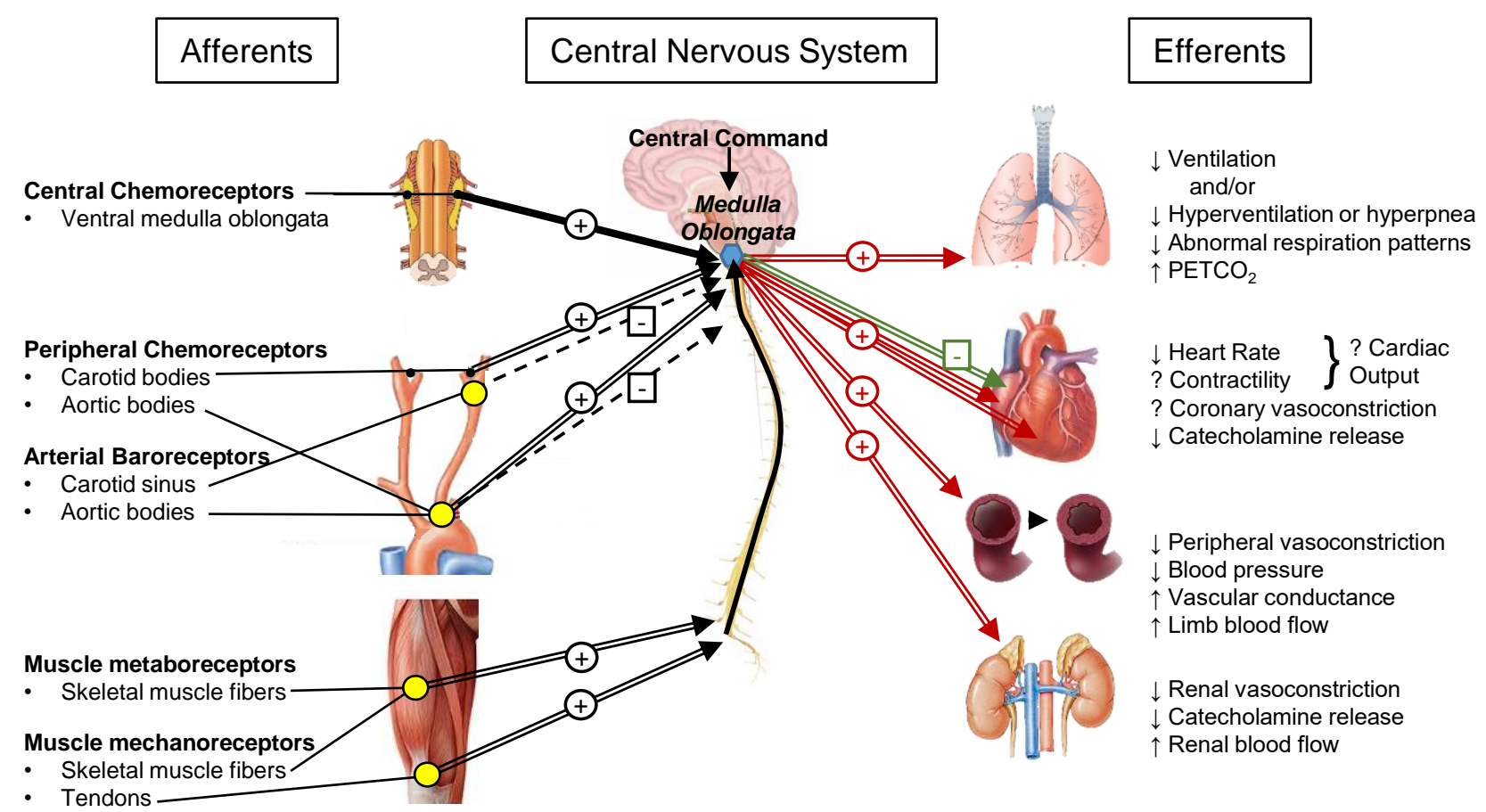

Fig. 2. Integration of cardiovascular autonomic reflexes in HFrEF after chronic exercise training. Afferent feedback is collected and integrated at the medulla oblongata of the brain stem (blue hexagon), where from efferent signals are outputted to various organs in response to the integration of the afferent and central information. Excitatory $(+)$ and inhibitory $(-)$ stimuli are shown for afferent feedback (black arrows), efferent sympathetic nerve activity (red arrows) and efferent parasympathetic nerve activity (green arrows). Exaggerated stimuli due to HFrEF are indicated as thick arrows, while blunted stimuli due to HFrEF are indicated as dashed thin arrows. Based on limited evidence, Fig. 2 represents the proposed changes following exercise training. The normalized signaling found following chronic exercise training is shown by parallel lines. Improved sensitivity of reflex receptors are indicated by a yellow dot.

\subsection{Exercise pressor reflex function after exercise training in $\mathrm{HFrEF}$}

Exercise training alters both the muscle metaboreflex and the muscle mechanoreflex in patients with HFrEF $[147,148]$. Six weeks of forearm training reduced the systolic and diastolic pressure, minute ventilation, respiration rate, and leg vascular resistance responses and increased the leg blood flow response to post-handgrip exercise circulatory occlusion in patients with HFrEF more so compared to healthy controls [148]. Further, these changes were accompanied by a decrease in sympathetic activation but without change in parasympathetic activation as measured by power spectral analysis of blood pressure low frequency components [148]. Antunes-Correa et al. [147] reported lower resting MSNA following exercise training (4-months combined aerobic, resistance, and flexibility training) compared to an untrained control HFrEF group; interestingly, however, the nature of the metaboreflex improvement further complicates the known literature surrounding muscle metaboreflex dysfunction in patients with HFrEF. During muscle metaboreflex activation via post-exercise circulatory occlusion, exercise trained patients with HFrEF reported heightening MSNA as well as increased transient receptor potential vanilloid type-1 (TRPV1) receptors and cannabi- noid receptor type-1 (CB1) in the vastus lateralis (trained muscle) whereas the untrained group saw no change in MSNA or the expression of either receptor compared to baseline testing [147]. This latter finding suggests that the blunted muscle metaboreflex response, found in some HFrEF studies [11,75,149] but not all [21,47,51,66,148], and confirmed at baseline testing in this study, is augmented with exercise training, thereby returning muscle metaboreflex dysfunction closer to normal function. It may be that HFrEF severity dictates the nature of muscle metaboreflex dysfunction [75], such that mild cases (e.g., NYHA class I-II) exhibit exaggerated responses that deteriorate as disease severity worsens, resulting in a blunted muscle metaboreflex response in more severe HFrEF conditions (e.g., NYHA class III-IV). In addition to muscle metaboreflex isolation, authors isolated the mechanoreflex with passive exercise and found decreased MSNA and expression of cyclooxygenase-2 (COX-2), prostaglandin-E2 receptor-4, and thromboxane-A2 receptors [147], each of which is involved in the COX pathway, a hypothesized mechanism behind mechanoreflex dysfunction in HFrEF. Recently, 6months of exercise training cardiac rehabilitation in patients with HFrEF not only improved peak $\mathrm{VO}_{2}$, resting and low-intensity exercising MSNA, but also attenuated 
the exaggerated MSNA during muscle metaboreflex activation compared to pre-training levels, although remained greater than healthy controls both pre- and post-training [150]. Aside from these high-impact data, little research has focused on the effect of exercise training on the exercise pressor reflex, the isolated muscle metaboreflex, or the isolated muscle mechanoreflex in patients with HFrEF. However, inferences may be made from animal HFrEF studies.

Two studies by Wang et al. [151,152] demonstrated that exercise training targets both the muscle metaboreflex and mechanoreflex in rat HFrEF models. Exercise training normalized pre-exercise blunted muscle metaboreflex (isolated via capsaicin injection) and decreased the pre-exercise exaggeration of the muscle mechanoreflex (isolated via contraction and passive stretch) in rats with $\mathrm{HFrEF}$, with no effects seen in sham rats post-training [152]. Mechanistically, exercise training improved the sensitization of both group III and IV afferents in the HFrEF rat models, corresponding to improved function of certain muscle metaboreflex (TRPV1) and mechanoreflex (P2X) receptors [151]. A review by the same group discussed the discrepancy between the observations of both blunted and exaggerated muscle metaboreflex responses in HFrEF, as well as potential mechanisms underlying the improved exercise pressor reflex response after exercise training, to a greater detail than may be covered herein [77].

\subsection{Arterial baroreflex function after exercise training in HFrEF}

The effect of exercise training on baroreflex function in patients with HFrEF is, surprisingly, vastly understudied in humans. To the knowledge of the authors, the only known study in human patients with HFrEF showing improved baroreflex sensitivity post-exercise training lacked a control group [153]. Fortunately, 6-months of combined aerobic and circuit training significantly improved baroreflex sensitivity with concomitant improvements in heart rate variability, cardiac presynaptic sympathetic innervation, increases in myocardial blood flow where it was reduced pre-training, however, without a statistically significant increase in peak $\mathrm{VO}_{2}$, in 12 NYHA class II-III HFrEF patients [153]. The very small sample and lack of a patient control group still enforce the need for updated evidence in baroreflex function post-exercise training in patients with HFrEF. Similarly, simulating exercise training with peroneal and tibial nerve electrical stimulation (transcutaneous electrical nerve stimulation; TENS) in patients with HFrEF effectively improved baroreflex sensitivity [96,154]. In contrast to the TENS groups, however, brief (2-day) exercise "training" had no effect on baroreflex sensitivity [96] and two weeks (4-6 sessions, 75-min each) of exercise training still failed to significantly improve baroreflex sensitivity in patients with HFrEF [154].

Despite the surprising lack of controlled, exercise training trials in patients with HFrEF on baroreflex sen- sitivity, evidence strongly suggests that exercise therapy improves baroreflex function in patients on the pre-HFrEF spectrum (e.g., hypertension, coronary artery disease, postmyocardial infarction, etc. $[155,156])$ as well as in animal HFrEF models [128,129,157-159], and thus strongly warrants clinical trials investigating the efficacy of improved baroreflex function and corresponding health benefits from exercise. However, given the lack of patient evidence, this section of the review will focus on animal based HFrEF studies.

Exercise training improved arterial baroreflex control of both renal sympathetic nerve activity and heart rate in HFrEF rabbits [158] and rats [160]. The latter finding was accompanied by improved aortic depressor nerve activity sensitivity following exercise training in rats with HFrEF [160], suggesting a role not only of carotid baroreceptors but of aortic baroreceptors in modulating heart rate and sympathetic outflow in HFrEF. Indeed, work by Liu et al. [159] demonstrated that atropine and metoprolol infusion modulated baroreflex control of heart rate through increased vagal tone, rather than reduced sympathetic outflow, following exercise training in HFrEF.

Exercise training normalized sympathetic outflow (resting renal sympathetic nerve activity) and arterial baroreflex function (attenuated maximum gain of heart rate and renal sympathetic nerve activity curves) in rabbits with HFrEF [128,157]. Further, angiotensin II type 1 receptor blockade in non-exercise trained HFrEF rabbits raised baroreceptor sensitivity approximating that of those exercise-trained rabbits with HFrEF; exercise in HFrEF rabbits also lowered circulating angiotensin II levels [157]. Mousa et al. [158] attributed their observed reduction in renal sympathetic nerve activity and elevation in baroreflex sensitivity in rabbits with HFrEF to concurrent reduction in circulating angiotensin II and angiotensin receptors in the central nervous system that occurs following exercise training. Thus, angiotensin II and the RAAS pathway is mechanistically tied to the dysfunctional pathophysiology of the arterial baroreflex in HFrEF. In rats, only endurance training improved cardiac autonomic control (increased baroreflex sensitivity) compared to moderate interval training, despite improved cardiac function and exercise capacity in both programs [129].

\subsection{Chemoreflex function after exercise training in $\mathrm{HFrEF}$}

Patients with HFrEF following carotid body resection exhibited significantly improved exercise time compared to pre-resection exercise time, reduced MSNA, and decreased peripheral chemosensitivity [115]. Although these are encouraging findings in human patients, this approach has been contested, for many reasons, in favour of exercise training [161]. Exercise training poses a less-invasive, more cost-effective, and in most cases, simpler alternative that may produce similar or better results, as well as more global physiological and health benefits (endothelial func- 
tion, peripheral blood flow distribution, skeletal muscle factors, and metabolic factors associated with reduced mortality).

Animal models have confirmed the efficacy of exercise training on attenuating exaggerated chemoreceptor sensitivity in HFrEF. Exaggerated peripheral chemosensitivity was attenuated by exercise training in rabbits with HFrEF [162]. Renal blood flow is classically reduced in the HFrEF condition due to exaggerated renal sympathetic nerve activity and consequent renal vasoconstriction, mediated in part by heightened peripheral chemoreceptor sensitivity. Exercise training attenuated peripheral chemoreflexmediated tonic reductions in renal blood flow in rabbits with HFrEF, as assessed by compared carotid-body chemoreceptor denervated animals with carotid-body intact animals; further, exercise training also attenuated hypoxia induced reductions in renal blood flow in the same HFrEF sample [163]. Along with improved exercise capacity, rabbits with pacing-induced HFrEF returned to pre-pacing levels of renal blood flow and vascular conductance during acute hypoxia after exercise training [127]. Thus, animal models have demonstrated that exercise training attenuates exaggerated peripheral chemoreceptor sensitivity found in HFrEF and improves physiological functions (increased peripheral blood flow) and autonomic signalling (reduced renal sympathetic nerve activity, increase baroreflex sensitivity). Unfortunately, in human patients with HFrEF, data supporting direct involvement and improvement of peripheral chemoreceptor function is lacking. Both interval training and combined interval and resistance training improved respiratory drive in patients with HFrEF [145]. Coats et al. [134] demonstrated reduced minute ventilation and the ventilation-carbon dioxide production slope post-exercise training, along with improved heart rate variability and reduced catecholamine levels, indicative of a shift in sympathovagal from sympathetic toward greater vagal tone, in patients with HFrEF.

\section{Central command}

Central command is critical to the autonomic response to exercise initation in healthy humans and is involved in arterial baroreflex resetting during exercise [164]. Despite the instrumental difficulty in differentiating between changes in central command from changes originating in other autonomic reflex segments (e.g., the mechanoreflex), evidence suggests central command is a modifiable and trainable portion of the autonomic control centre [165]. Using electrically evoked skeletal muscle contractions to isolate central command, routine exercise training was shown to decrease central command input during exercise without a concomitant change in exercise pressor reflex in healthy humans [165]. However, evidence of central command changes and the effects of exercise training in HFrEF is limited. Central command was shown to contribute to the exaggerated sympathetic nerve activity during exercise that is characteristic of HFrEF by simulating exercise with mesencephalic locomotor region stimulation in decerebate, ischemic HFrEF rats, and observing fictional-exericse-induced elevated renal and lumbar sympathetic nerve activity [166]. In humans with severe HFrEF, the methodology was unable to differentiate between central command and the mechanoreflex as the primary driver of elevated MSNA during exercise [75]. Interestingly, central command in patients with $\mathrm{HF}$ and preserved ejection fraction (HFpEF) was not different from healthy controls despite a lower exercise heart rate [167]; however, the such investigations to better understand the role of central command on exercise pathophysiology in patients with HFrEF is lacking and merits further attention.

\section{Clinical implications}

Exaggerated sympathoexcitation and depressed vagal tone, as a result of exercise autonomic reflex dysfunction, are proven contributors to prognosis, exercise intolerance, and survival in patients with $\operatorname{HFrEF}[21,32,47]$. It may be clinically prudent to treat the cause(s) of the sympathoexcitation in HFrEF rather than, or at least in addition to, its consequences (e.g., increased MSNA, vasoconstriction, blood pressure) $[47,48]$. As discussed, potential mechanisms for each reflex may include skeletal muscle abnormalities, arterial stiffness, chronic or intermittent hypercapnia, respiratory acidosis or hypoxemia, and chronic oxidative stress. Exercise training may target some or all of these potential causes for afferent dysfunction, and may attenuate or reverse chronic sympathoexcitation and enhance vagal tone [21]. Other therapies targeting afferent, central, and efferent portions of the reflex loop (Fig. 1) are emerging [21].

\section{Future needs and directions}

Exercise training is an effective and low-cost nonpharmacologic therapeutic option for people living with HFrEF. Exercise training improves exercise capacity, which is related with better outcomes in patients with HF $[168,169]$. This non-invasive, affordable, and readily accessible therapy has the potential to be more successful compared to devices and medications for a number of reasons, including but not limited to (a) the effects of exercise target multiple organs and signaling systems, resulting in a "global" improvement; (b) regular exercise improves perceived quality of life and mental health, and (c) exercise training impacts not only the HFrEF sequelae, but other comorbidities and thus lifts the overall burden of health.

The effect of exercise training on the function of each reflex [170], rather than the physiological consequence (e.g., MSNA, heart rate variability, heart rate recovery, etc. [126]) is relatively understudied and not completely known. For example, the recent meta-analysis reports only heart rate recovery, MSNA, and heart rate variability: all indirect measures of autonomic nervous system activity and not used to differentiate between sympathetic and parasympathetic activity, nor tied to any one reflex pathway [126]. 
This may be due to the technical difficulty and invasiveness in obtaining direct measures, coupled with the challenge of obtaining meaningful data across a wide variety of comorbidities (e.g., a recent mean of 5 comobidities [169]) that often accompany HFrEF. Medication usage presents another challenge with evaluating the effectiveness of exercise training trials as certain medications (e.g., beta-blockers) may negate or mask favourable sympathovagal shifts. The effect of exercise training on peripheral chemoreflex function and regulation of cardiovascular hemodynamics is understudied in humans with HFrEF. Further, Pearson and Smart [126] report that the majority of studies and randomized controlled trials on exercise therapy on autonomic function in HFrEF lack sufficient allocation concealment, intention-to-treat analysis, control group physical activity monitoring, and considerations regarding relative exercise intensity and accurate energy expenditure. Clearly, both study design and the primary outcome have room for improvement in future randomized controlled trials in exercise training effects on autonomic function in patients with HFrEF.

Mechanistic animal studies have yet to be confirmed in patients with HFrEF; cardiac catheterization during exercise reflex activation may determine the extent of reflex modulation of coronary vasoconstriction and altered ventricular function during exercise in HFrEF [73]. As well, despite the mounting evidence supporting oxidative stress involvement in chemoreflex exaggeration, there is limited data on the effects of exercise training on chemoreflex function and oxidative stress in patients with HFrEF [30]. Other therapies currently under or for future investigation that modulate reflex physiology may include carotid body resection, ablation or desensitization (early findings suggest unilateral vs. bilateral for patient safety [115]), arterial baroreceptor stimulation, vagal nerve stimulation, central acting parasympathetic-mimicking or sympatho-modulatory medications, efferent renal nerve ablation, acetylcholinesterase inhibition, nicotinic receptor agonists, and beta-adrenergic receptor blockers [21].

Randomized controlled trials are still needed to phenotype autonomic dysfunction to select the appropriate therapeutic approach in HFrEF. The issue of autonomic dysfunction in HFrEF becomes more complicated when comorbidities that also relate to autonomic dysfunction (e.g., hypertension, obesity, diabetes, etc.) $[126,171]$ are added to the equation. The combined effects of multiple morbidities are not well understood and thus requires larger spectrum of inclusion criteria in experimental designs to increase our body of evidence. Patient sex is often overlooked in heart failure research despite the well-acknowledged fact that cardiovascular health and autonomic function is different in females compared to males. As the majority of heart failure studies are primarily male participants, future trials with sex-based comparisons are needed to elucidate any potential sex differences to better treat female patients in the future. Finally,
HFpEF and mid-range ejection fraction (HFmEF) are increasingly clinically recognized and studied. However, the evidence around autonomic dysfunction is vastly disproportionally in patients and animals with HFrEF compared to their phenotypic counterparts. Future research should address the gap in literature surrounding HFpEF and HFmEF autonomic function, as well as phenotype-based studies to liken and differentiate the diseases from one another so as to improve future therapy targets on a phenotype-specific basis.

\section{Conclusions}

Fundamentally, reflex dysfunction may be adaptive at the onset of cardiac failure, but inter-reflex coordination is progressively lost, and thus autonomic dysfunction occurs. The exercise pressor reflex is exaggerated and enhances mean arterial pressure, MSNA, peripheral and likely cardiac vasoconstriction during exercise in HFrEF. Conversely, the exercise pressor reflex may be attenuated in more severe HFrEF. Baroreflex control of heart rate is blunted in HFrEF, as is its ability to buffer the metaboreflex, resulting in elevated resting and exercise heart rate and mean arterial pressure. Chemoreflex hyperactivity induces respiratory disorders, elevated heart rate, and greater vasoconstriction at rest and during exercise. Cumulatively, cardiovascular autonomic reflex dysfunction in HFrEF exaggerates sympathoexcitation to cardiac, respiratory, renal, vascular, and skeletal muscular tissues. The cardiovascular autonomic reflex dysfunction thus critically contributes to exercise intolerance and prognosis in HFrEF patients.

\section{Author contributions}

Conceptualization-NGB, DDM, HH, and CRT; methodology-NGB, DDM, HH, and CRT; investigation-NGB; data curation-NGB; writingNGB; review and editing-NGB, DDM, HH, and CRT; visualization - NGB and CRT; supervision - $\mathrm{CRT}$; funding acquisition-NGB and CRT. All authors have read and agreed to the published version of the manuscript.

\section{Ethics approval and consent to participate}

Not applicable.

\section{Acknowledgment}

Not applicable.

\section{Funding}

NGB is funded by a Natural Sciences and Engineering Research Council of Canada Doctoral Postgraduate Scholarship. CRT is funded by the Saskatchewan Health Research Foundation (Establishment Grant \#3468) and the Heart and Stroke Foundation of Canada Grant-in-Aid (G16-00014255). 


\section{Conflict of interest}

The authors declare no conflict of interest.

\section{References}

[1] Yancy CW, Jessup M, Bozkurt B, Butler J, Casey DE, Drazner MH, et al. 2013 ACCF/AHA guideline for the management of heart failure: a report of the American College of Cardiology Foundation/American Heart Association Task Force on Practice Guidelines. Journal of the American College of Cardiology. 2013; 62: e147-e239.

[2] Ponikowski P, Anker SD, AlHabib KF, Cowie MR, Force TL, Hu $\mathrm{S}$, et al. Heart failure: preventing disease and death worldwide. ESC Heart Failure. 2014; 1: 4-25.

[3] Scott AC, Francis DP, Davies LC, Ponikowski P, Coats AJ, Piepoli MF. Contribution of skeletal muscle 'ergoreceptors' in the human leg to respiratory control in chronic heart failure. The Journal of Physiology. 2001; 529 Pt 3: 863-870.

[4] Scott AC, Francis DP, Coats AJS, Piepoli MF. Reproducibility of the measurement of the muscle ergoreflex activity in chronic heart failure. European Journal of Heart Failure. 2003; 5: 453461.

[5] Haykowsky MJ, Tomczak CR, Scott JM, Paterson DI, Kitzman DW. Determinants of exercise intolerance in patients with heart failure and reduced or preserved ejection fraction. Journal of Applied Physiology. 2015; 119: 739-744.

[6] Kitzman DW, Little WC, Brubaker PH, Anderson RT, Hundley WG, Marburger CT, et al. Pathophysiological characterization of isolated diastolic heart failure in comparison to systolic heart failure. Journal of the American Medical Association. 2002; 288: 2144-2150.

[7] Corra U, Piepoli MF, Adamopoulos S, Agostoni P, Coats AJS, Conraads $\mathrm{V}$, et al. Cardiopulmonary exercise testing in systolic heart failure in 2014: the evolving prognositc role. A position paper from the Committee on Exercise Physiology and Training of the Heart Failure Association of the European Society of Cardiology. European Journal of Heart Failure. 2014; 16: 929-941.

[8] Tabet J, Meurin P, Benzidi Y, Beauvais F, Ben Driss A, Weber H, et al. Greater prognostic value of peak VO2 after exercise training program completion in heart failure patients. International Journal of Cardiology. 2013; 168: 4139-4144.

[9] Notarius CF, Spaak J, Morris BL, Floras JS. Comparison of muscle sympathetic activity in ischemic and nonischemic heart failure. Journal of Cardiac Failure. 2007; 13: 470-475.

[10] Notarius CF, Atchison DJ, Rongen GA, Floras JS. Effect of adenosine receptor blockade with caffeine on sympathetic response to handgrip exercise in heart failure. American Journal of Physiology Heart and Circulatory Physiology. 2001; 281: H1312-H1318.

[11] Sterns DA, Ettinger SM, Gray KS, Whisler SK, Mosher TJ, Smith MB, et al. Skeletal muscle metaboreceptor excercise responses are attenuated in heart failure. Circulation. 1991; 84: 2034-2039.

[12] Di Vanna A, Braga AMFW, Laterza MC, Ueno LM, Rondon MUPB, Barretto ACP, et al. Blunted muscle vasodilatation during chemoreceptor stimulation in patients with heart failure. American Journal of Physiology Heart and Circulatory Physiology. 2007; 293: H846-H852.

[13] Narkiewicz K, Pesek CA, van de Borne PJ, Kato M, Somers VK. Enhanced sympathetic and ventilatory responses to central chemoreflex activation in heart failure. Circulation. 1999; 100: 262-267.

[14] Ferguson DW, Berg WJ, Sanders JS, Kempf JS. Clinical and hemodynamic correlates of sympathetic nerve activity in normal humans and patients with heart failure: Evidence from direct micronenrographic recordings. Journal of the American College of
Cardiology. 1990; 16: 1125-1134.

[15] Notarius CF, Ando S, Rongen GA, Floras JS. Resting muscle sympathetic nerve activity and peak oxygen uptake in heart failure and normal subjects. European Heart Journal. 1999; 20: 880-887.

[16] Reading JL, Goodman JM, Plyley MJ, Floras JS, Liu PP, McLaughlin PR, et al. Vascular conductance and aerobic power in sedentary and active subjects and heart failure patients. Journal of Applied Physiology. 1993; 74: 567-573.

[17] Shoemaker JK, Naylor HL, Hogeman CS, Sinoway LI. Blood flow dynamics in heart failure. Circulation. 1999; 99: 30023008 .

[18] Sullivan MJ, Knight JD, Higginbotham MB, Cobb FR. Relation between central and peripheral hemodynamics during exercise in patients with chronic heart failure: Muscle blood is reduced with maintenance of arterial perfusion pressure. Circulation. 1989; 80: 769-781.

[19] Notarius CF, Atchison DJ, Floras JS. Impact of heart failure and exercise capacity on sympathetic response to handgrip exercise. American Journal of Physiology Heart and Circulatory Physiology. 2001; 280: H969-H976.

[20] Kaye DM, Lefkovits J, Jennings GL, Bergin P, Broughton A, Esler MD. Adverse consequences of high sympathetic nervous activity in the failing human heart. Journal of the American College of Cardiology. 1995; 26: 1257-1263.

[21] Floras JS, Ponikowski P. The sympathetic/parasympathetic imbalance in heart failure with reduced ejection fraction. European Heart Journal. 2015; 36: 1974-182b.

[22] Fisher JP, Young CN, Fadel PJ. Autonomic adjustments to exercise in humans. Comprehensive Physiology. 2015; 5: 475-512.

[23] Warner HR, Cox A. A mathematical model of heart rate control by sympathetic and vagus efferent information. Journal of Applied Physiology. 1962; 17: 349-355.

[24] Fagraeus L, Linnarsson D. Autonomic origin of heart rate fluctuations at the onset of muscular exercise. Journal of Applied Physiology. 1976; 40: 679-682.

[25] Brede M, Wiesmann F, Jahns R, Hadamek K, Arnolt C, Neubauer S, et al. Feedback inhibition of catecholamine release by two different alpha2-adrenoceptor subtypes prevents progression of heart failure. Circulation. 2002; 106: 2491-2496.

[26] Cohn JN, Levine TB, Olivari MT, Garberg V, Lura D, Francis GS, et al. Plasma norepinephrine as a guide to prognosis in patients with chronic congestive heart failure. The New England Journal of Medicine. 1984; 311: 819-823.

[27] Floras JS. Clinical aspects of sympathetic activation and parasympathetic withdrawal in heart failure. Journal of the American College of Cardiology. 1993; 22: 72A-84A.

[28] Floras JS. Sympathetic Nervous System Activation in Human Heart Failure: clinical implications of an updated model. Journal of the American College of Cardiology. 2009; 54: 375-385.

[29] Binkley PF, Nunziata E, Haas GJ, Nelson SD, Cody RJ. Parasympathetic withdrawal is an integral component of autonomic imbalance in congestive heart failure: demonstration in human subjects and verification in a paced canine model of ventricular failure. Journal of the American College of Cardiology. 1991; 18: 464-472.

[30] Andrade DC, Arce-Alvarez A, Toledo C, Díaz HS, Lucero C, Quintanilla RA, et al. Revisiting the physiological effects of exercise training on autonomic regulation and chemoreflex control in heart failure: does ejection fraction matter? American Journal of Physiology. Heart and Circulatory Physiology. 2018; 314 : H464-H474.

[31] Triposkiadis F, Karayannis G, Giamouzis G, Skoularigis J, Louridas G, Butler J. The sympathetic nervous system in heart failure physiology, pathophysiology, and clinical implications. Journal of the American College of Cardiology. 2009; 54: 1747 - 
1762.

[32] Toschi-Dias E, Rondon MUPB, Cogliati C, Paolocci N, Tobaldini E, Montano N. Contribution of Autonomic Reflexes to the Hyperadrenergic State in Heart Failure. Frontiers in Neuroscience. 2017; 11: 162.

[33] Kleber FX, Vietzke G, Wernecke KD, Bauer U, Opitz C, Wensel $\mathrm{R}$, et al. Impairment of ventilatory efficiency in heart failure: prognostic impact. Circulation. 2000; 101: 2803-2809.

[34] Vazir A, Claggett B, Jhund P, Castagno D, Skali H, Yusuf S, et al. Prognostic importance of temporal changes in resting heart rate in heart failure patients: an analysis of the CHARM program. European Heart Journal. 2015; 36: 669-675.

[35] Opdahl A, Ambale Venkatesh B, Fernandes VRS, Wu CO, Nasir $\mathrm{K}$, Choi E, et al. Resting heart rate as predictor for left ventricular dysfunction and heart failure: MESA (Multi-Ethnic Study of Atherosclerosis). Journal of the American College of Cardiology. 2014; 63: 1182-1189.

[36] Roche F, Pichot V, Da Costa A, Isaaz K, Costes F, Dall'Acqua $\mathrm{T}$, et al. Chronotropic incompetence response to exercise in congestive heart failure, relationship with the cardiac autonomic status. Clinical Physiology. 2001; 21: 335-342.

[37] Ponikowski P, Chua TP, Piepoli M, Ondusova D, Webb-Peploe $\mathrm{K}$, Harrington $\mathrm{D}$, et al. Augmented peripheral chemosensitivity as a potential input to baroreflex impairment and autonomic imbalance in chronic heart failure. Circulation. 1997; 96: 25862594.

[38] Shah SA, Kambur T, Chan C, Herrington DM, Liu K, Shah SJ. Relation of short-term heart rate variability to incident heart failure (from the Multi-Ethnic Study of Atherosclerosis). The American Journal of Cardiology. 2013; 112: 533-540.

[39] Agostoni P, Contini M, Magini A, Apostolo A, Cattadori G, Bussotti $\mathrm{M}$, et al. Carvedilol reduces exercise-induced hyperventilation: a benefit in normoxia and a problem with hypoxia. European Journal of Heart Failure. 2006; 8: 729-735.

[40] Agostoni P, Pellegrino R, Conca C, Rodarte JR, Brusasco V. Exercise hyperpnea in chronic heart failure: relationships to lung stiffness and expiratory flow limitation. Journal of Applied Physiology. 2002; 92: 1409-1416.

[41] Kaye DM, Lambert GW, Lefkovits J, Morris M, Jennings G, Esler MD. Neurochemical evidence of cardiac sympathetic activation and increased central nervous system norepinephrine turnover in severe congestive heart failure. Journal of the American College of Cardiology. 1994; 23: 570-578.

[42] Negrao CE, Middlekauff HR, Gomes-Santos IL, AntunesCorrea LM. Effects of exercise training on neurovascular control and skeletal myopathy in systolic heart failure. American Journal of Physiology-Heart and Circulatory Physiology. 2015; 308: H792-H802.

[43] Negrao CE, Middlekauff HR. Adaptations in autonomic function during exercise training in heart failure. Heart Failure Reviews. 2008; 13: 51-60.

[44] Alam M, Smirk FH. Observations in man upon a blood pressure raising reflex arising from the voluntary muscles. The Journal of Physiology. 2007; 89: 372-383.

[45] Kao FF, Michel CC, Mei SS, Li WK. Somatic afferent influence on respiration. Annals of the New York Academy of Sciences. 1963; 109: 696-711.

[46] Sinoway LI, Li J. A perspective on the muscle reflex: implications for congestive heart failure. Journal of Applied Physiology. 2005; 99: 5-22.

[47] Piepoli MF, Dimopoulos K, Concu A, Crisafulli A. Cardiovascular and ventilatory control during exercise in chronic heart failure: Role of muscle reflexes. International Journal of Cardiology. 2008; 130: 3-10.

[48] Belli JFC, Bacal F, Bocchi EA, Guimarães GV. Ergoreflex activity in heart failure. Arquivos Brasileiros De Cardiologia. 2011;
97: 171-178.

[49] Shoemaker JK, Kunselman AR, Silber DH, Sinoway LI. Maintained exercise pressor response in heart failure. Journal of Applied Physiology. 1998; 85: 1793-1799.

[50] Middlekauff HR, Chiu J, Hamilton MA, Fonarow GC, Maclellan WR, Hage A, et al. Muscle mechanoreceptor sensitivity in heart failure. American Journal of Physiology Heart and Circulatory Physiology. 2004; 287: H1937-H1943.

[51] Piepoli M, Ponikowski P, Clarka AL, Banasiak W, Capucci A, Coats AJS. A neural link to explain the "muscle hypothesis" of exercise intolerance in chronic heart failure. American Heart Journal. 1999; 137: 1050-1056.

[52] Amann M, Venturelli M, Ives SJ, Morgan DE, Gmelch B, Witman MAH, et al. Group III/IV muscle afferents impair limb blood in patients with chronic heart failure. International Journal of Cardiology. 2014; 174: 368-375.

[53] Esposito F, Reese V, Shabetai R, Wagner PD, Richardson RS. Isolated quadriceps training increases maximal exercise capacity in chronic heart failure: the role of skeletal muscle convective and diffusive oxygen transport. Journal of the American College of Cardiology. 2011; 58: 1353-1362.

[54] Mettauer B, Zoll J, Sanchez H, Lampert E, Ribera F, Veksler $\mathrm{V}$, et al. Oxidative capacity of skeletal muscle in heart failure patients versus sedentary or active control subjects. Journal of the American College of Cardiology. 2001; 38: 947-954.

[55] Weiss K, Schär M, Panjrath GS, Zhang Y, Sharma K, Bottomley PA, et al. Fatigability, Exercise Intolerance, and Abnormal Skeletal Muscle Energetics in Heart Failure. Circulation. Heart Failure. 2017; 10: 1-12.

[56] Esposito F, Mathieu-Costello O, Shabetai R, Wagner PD, Richardson RS. Limited maximal exercise capacity in patients with chronic heart failure: partitioning the contributors. Journal of the American College of Cardiology. 2010; 55: 1945-1954.

[57] Bowen TS, Cannon DT, Murgatroyd SR, Birch KM, Witte KK, Rossiter HB. The intramuscular contribution to the slow oxygen uptake kinetics during exercise in chronic heart failure is related to the severity of the condition. Journal of Applied Physiology. 2012; 112: 378-387.

[58] Middlekauff HR, Nitzsche EU, Hoh CK, Hamilton MA, Fonarow GC, Hage A, et al. Exaggerated muscle mechanoreflex control of reflex renal vasoconstriction in heart failure. Journal of Applied Physiology. 2001; 90: 1714-1719.

[59] Smith SA, Mammen PPA, Mitchell JH, Garry MG. Role of the exercise pressor reflex in rats with dilated cardiomyopathy. Circulation. 2003; 108: 1126-1132.

[60] Keller-Ross ML, Johnson BD, Joyner MJ, Olson TP. Influence of the metaboreflex on arterial blood pressure in heart failure patients. American Heart Journal. 2014; 167: 521-528.

[61] Hanna RL, Kaufman MP. Activation of thin-fiber muscle afferents by a P2X agonist in cats. Journal of Applied Physiology. 2004; 96: 1166-1169.

[62] Angius L, Crisafulli A. Exercise intolerance and fatigue in chronic heart failure: is there a role for group IIIIV afferent feedback? European Journal of Preventive Cardiology. 2020; 27: 1862-1872.

[63] Van Iterson EH, Snyder EM, Johnson BD, Olson TP. Influence of the Metaboreflex on Pulmonary Vascular Capacitance in Heart Failure. Medicine and Science in Sports and Exercise. 2016; 48: 353-362.

[64] Crisafulli A, Salis E, Tocco F, Melis F, Milia R, Pittau G, et al. Impaired central hemodynamic response and exaggerated vasoconstriction during muscle metaboreflex activation in heart failure patients. American Journal of Physiology Heart and Circulatory Physiology. 2007; 292: H2988-H2996.

[65] Crisafulli A, Scott AC, Wensel R, Davos CH, Francis DP, Pagliaro $\mathrm{P}$, et al. Muscle metaboreflex-induced increases in 
stroke volume. Medicine and Science in Sports and Exercise. 2003; 35: 221-8; discussion 229.

[66] scott AC, Davies LC, Coats AJS, Piepoli M. Relationship of skeletal muscle metaboreceptors in the upper and lower limbs with the respiratory control in patients with heart failure. Clinical Science. 2002; 102: 23.

[67] Ponikowski PP, Chua TP, Francis DP, Capucci A, Coats AJ, Piepoli MF. Muscle ergoreceptor overactivity reflects deterioration in clinical status and cardiorespiratory reflex control in chronic heart failure. Circulation. 2001; 104: 2324-2330.

[68] Pardaens S, Vanderheyden M, Calders P, Willems A, Bartunek J, de Sutter J. Activation of the ergoreceptors in cardiac patients with and without heart failure. Journal of Cardiac Failure. 2014; 20: 747-754.

[69] Ansorge EJ, Augustyniak RA, Perinot ML, Hammond RL, Kim J, Sala-Mercado JA, et al. Altered muscle metaboreflex control of coronary blood flow and ventricular function in heart failure. American Journal of Physiology. Heart and Circulatory Physiology. 2005; 288: H1381-H1388.

[70] Hammond RL, Augustyniak RA, Rossi NF, Churchill PC, Lapanowski K, O'Leary DS. Heart failure alters the strength and mechanisms of the muscle metaboreflex. American Journal of Physiology. Heart and Circulatory Physiology. 2000; 278: H818-H828.

[71] O'Leary DS, Sala-Mercado JA, Augustyniak RA, Hammond RL, Rossi NF, Ansorge EJ. Impaired muscle metaboreflexinduced increases in ventricular function in heart failure. American Journal of Physiology. Heart and Circulatory Physiology. 2004; 287: H2612-H2618.

[72] Barrett-O'Keefe Z, Lee JF, Berbert A, Witman MAH, NativiNicolau J, Stehlik J, et al. Metaboreceptor activation in heart failure with reduced ejection fraction: Linking cardiac and peripheral vascular hemodynamics. Experimental Physiology. 2018; 103: 807-818.

[73] Coutsos M, Sala-Mercado JA, Ichinose M, Li Z, Dawe EJ, O'Leary DS. Muscle metaboreflex-induced coronary vasoconstriction limits ventricular contractility during dynamic exercise in heart failure. American Journal of Physiology. Heart and Circulatory Physiology. 2013; 304: H1029-H1037.

[74] Koshy A, Okwose NC, Nunan D, Toms A, Brodie DA, Doherty $\mathrm{P}$, et al. Association between heart rate variability and haemodynamic response to exercise in chronic heart failure. Scandinavian Cardiovascular Journal. 2019; 53: 77-82.

[75] Negrão CE, Rondon MU, Tinucci T, Alves MJ, Roveda F, Braga $\mathrm{AM}$, et al. Abnormal neurovascular control during exercise is linked to heart failure severity. American Journal of Physiology. Heart and Circulatory Physiology. 2001; 280: H1286-H1292.

[76] Silber DH, Sutliff G, Yang QX, Smith MB, Sinoway LI, Leuenberger UA. Altered mechanisms of sympathetic activation during rhythmic forearm exercise in heart failure. Journal of Applied Physiology. 1998; 84: 1551-1559.

[77] Wang HJ, Zucker IH, Wang W. Muscle reflex in heart failure : the role of exercise training. Frontiers in Physiology. 2012; 3: 398.

[78] Ferguson DW, Berg WJ, Roach PJ, Oren RM, Mark AL. Effects of heart failure on baroreflex control of sympathetic neural activity. The American Journal of Cardiology. 1992; 69: 523-531.

[79] Grassi G, Seravalle G, Bertinieri G, Turri C, Stella ML, Scopelliti $\mathrm{F}$, et al. Sympathetic and reflex abnormalities in heart failure secondary to ischaemic or idiopathic dilated cardiomyopathy. Clinical Science. 2001; 101: 141-146.

[80] Eckberg DL, Drabinsky M, Braunwald E. Defective cardiac parasympathetic control in patients with heart disease. The New England Journal of Medicine. 1971; 285: 877-883.

[81] La Rovere MT, Pinna GD, Maestri R, Robbi E, Caporotondi A, Guazzotti G, et al. Prognostic implications of baroreflex sensi- tivity in heart failure patients in the beta-blocking era. Journal of the American College of Cardiology. 2009; 53: 193-199.

[82] Gronda E, Francis D, Zannad F, Hamm C, Brugada J, Vanoli E. Baroreflex activation therapy: a new approach to the management of advanced heart failure with reduced ejection fraction. Journal of Cardiovascular Medicine. 2018; 18: 641-649.

[83] Ponikowski P, Francis DP, Piepoli MF, Davies LC, Chua TP, Davos $\mathrm{CH}$, et al. Enhanced ventilatory response to exercise in patients with chronic heart failure and preserved exercise tolerance: marker of abnormal cardiorespiratory reflex control and predictor of poor prognosis. Circulation. 2001; 103: 967-972.

[84] Radaelli A, Castiglioni P, Balestri G, Cesana F, De Carlini C, Soriano $\mathrm{F}$, et al. Increased pulse wave velocity and not reduced ejection fraction is associated with impaired baroreflex control of heart rate in congestive heart failure. Journal of Hypertension. 2010; 28: 1908-1912.

[85] Patel H, Ozdemir BA, Patel M, Xiao HB, Poole-Wilson PA, Rosen SD. Impairment of autonomic reactivity is a feature of heart failure whether or not the left ventricular ejection fraction is normal. International Journal of Cardiology. 2011; 151: 3439.

[86] Seravalle G, Quarti-Trevano F, Dell'Oro R, Gronda E, Spaziani $\mathrm{D}$, Facchetti $\mathrm{R}$, et al. Sympathetic and baroreflex alterations in congestive heart failure with preserved, midrange and reduced ejection fraction. Journal of Hypertension. 2019; 37: 443-448.

[87] Dibner-Dunlap ME, Thames MD. Baroreflex control of renal sympathetic nerve activity is preserved in heart failure despite reduced arterial baroreceptor sensitivity. Circulation Research. 1989; 65: 1526-1535.

[88] White CW. Abnormalities in baroreflex control of heart rate in canine heart failure. The American Journal of Physiology. 1981; 240: H793-H799.

[89] Wang W, Chen JS, Zucker IH. Carotid sinus baroreceptor reflex in dogs with experimental heart failure. Circulation Research. 1991; 68: 1294-1301.

[90] Wilson JR, Lanoce V, Frey MJ, Ferraro N. Arterial baroreceptor control of peripheral vascular resistance in experimental heart failure. American Heart Journal. 1990; 119: 1122-1130.

[91] Olivier NB, Stephenson RB. Characterization of baroreflex impairment in conscious dogs with pacing-induced heart failure. The American Journal of Physiology. 1993; 265: R1132R1140.

[92] Kim J, Augustyniak RA, Sala-Mercado JA, Hammond RL, Ansorge EJ, Rossi NF, et al. Heart failure alters the strength and mechanisms of arterial baroreflex pressor responses during dynamic exercise. American Journal of Physiology. Heart and Circulatory Physiology. 2004; 287: H1682-H1688.

[93] Ichinose M, Sala-Mercado JA, Coutsos M, Li Z, Ichinose TK, Dawe E, et al. Dynamic cardiac output regulation at rest, during exercise, and muscle metaboreflex activation: impact of congestive heart failure. American Journal of Physiology. Regulatory, Integrative and Comparative Physiology. 2012; 303: R757R768.

[94] Kim J, Sala-Mercado JA, Hammond RL, Rodriguez J, Scislo TJ, O'Leary DS. Attenuated arterial baroreflex buffering of muscle metaboreflex in heart failure. American Journal of Physiology. Heart and Circulatory Physiology. 2005; 289: H2416-H2423.

[95] Kaur J, Krishnan AC, Senador D, Alvarez A, Hanna HW, O'Leary DS. Altered arterial baroreflex-muscle metaboreflex interaction in heart failure. American Journal of Physiology-Heart and Circulatory Physiology. 2018; 315: H1383-H1392.

[96] Gademan MGJ, Sun Y, Han L, Valk VJ, Schalij MJ, van Exel HJ, et al. Rehabilitation: Periodic somatosensory stimulation increases arterial baroreflex sensitivity in chronic heart failure patients. International Journal of Cardiology. 2011; 152: 237-241.

[97] Abraham WT, Zile MR, Weaver FA, Butter C, Ducharme A, 
Halbach M, et al. Baroreflex Activation Therapy for the Treatment of Heart Failure with a Reduced Ejection Fraction. JACC: Heart Failure. 2015; 3: 487-496.

[98] Zannad F, De Ferrari GM, Tuinenburg AE, Wright D, Brugada $\mathrm{J}$, Butter C, et al. Chronic vagal stimulation for the treatment of low ejection fraction heart failure: results of the NEural Cardiac TherApy for Heart Failure (NECTAR-HF) randomized controlled trial. European Heart Journal. 2015; 36: 425-433.

[99] De Ferrari GM, Crijns HJGM, Borggrefe M, Milasinovic G, Smid J, Zabel M, et al. Chronic vagus nerve stimulation: a new and promising therapeutic approach for chronic heart failure. European Heart Journal. 2011; 32: 847-855.

[100] Gold MR, Van Veldhuisen DJ, Hauptman PJ, Borggrefe M, Kubo SH, Lieberman RA, et al. Vagus Nerve Stimulation for the Treatment of Heart Failure: the INOVATE-HF Trial. Journal of the American College of Cardiology. 2016; 68: 149-158.

[101] Normand C, Kaye DM, Povsic TJ, Dickstein K. Beyond pharmacological treatment: an insight into therapies that target specific aspects of heart failure pathophysiology. Lancet. 2019; 393: 1045-1055.

[102] Schultz HD, Marcus NJ, Del Rio R. Mechanisms of carotid body chemoreflex dysfunction during heart failure. Experimental Physiology. 2015; 100: 124-129.

[103] Somers VK, Mark AL, Zavala DC, Abboud FM. Contrasting effects of hypoxia and hypercapnia on ventilation and sympathetic activity in humans. Journal of Applied Physiology. 1989; 67: 2101-2106

[104] Somers VK, Mark AL, Zavala DC, Abboud FM. Influence of ventilation and hypocapnia on sympathetic nerve responses to hypoxia in normal humans. Journal of Applied Physiology. 1989; 67: 2095-2100.

[105] Oldenburg O, Spießhöfer J, Fox H, Bitter T, Horstkotte D. Cheyne-Stokes respiration in heart failure: friend or foe? Hemodynamic effects of hyperventilation in heart failure patients and healthy volunteers. Clinical Research in Cardiology. 2015; 104 : 328-333.

[106] Ueno H, Asanoi H, Yamada K, Oda Y, Takagawa J, Kameyama $\mathrm{T}$, et al. Attenuated respiratory modulation of chemoreflexmediated sympathoexcitation in patients with chronic heart failure. Journal of Cardiac Failure. 2004; 10: 236-243.

[107] Wasserman K, Zhang Y, Gitt A, Belardinelli R, Koike A, Lubarsky L, et al. Lung Function and Exercise Gas Exchange in Chronic Heart Failure. Circulation. 1997; 96: 2221-2227.

[108] Fanfulla F, Mortara A, Maestri R, Pinna GD, Bruschi C, Cobelli F, et al. The Development of Hyperventilation in Patients with Chronic Heart Failure and Cheyne-Stokes Respiration: a possible role of chronic hypoxia. Chest. 1998; 114: 1083-1090.

[109] Chua TP, Clark AL, Amadi AA, Coats AJ. Relation between chemosensitivity and the ventilatory response to exercise in chronic heart failure. Journal of the American College of Cardiology. 1996; 27: 650-657.

[110] Stickland MK, Miller JD, Smith CA, Dempsey JA. Carotid chemoreceptor modulation of regional blood flow distribution during exercise in health and chronic heart failure. Circulation Research. 2007; 100: 1371-1378.

[111] Machado AC, Vianna LC, Gomes EAC, Teixeira JAC, Ribeiro ML, Villacorta $\mathrm{H}$, et al. Carotid chemoreflex and muscle metaboreflex interact to the regulation of ventilation in patients with heart failure with reduced ejection fraction. Physiological Reports. 2020; 8: e14361.

[112] Del Rio R, Marcus NJ, Schultz HD. Carotid Chemoreceptor Ablation Improves Survival in Heart Failure. Journal of the American College of Cardiology. 2013; 62: 2422-2430.

[113] Marcus NJ, Del Rio R, Schultz EP, Xia X, Schultz HD. Carotid body denervation improves autonomic and cardiac function and attenuates disordered breathing in congestive heart failure. The
Journal of Physiology. 2014; 592: 391-408.

[114] Schultz HD, Marcus NJ, Del Rio R. Role of the Carotid Body Chemoreflex in the Pathophysiology of Heart Failure: A Perspective from Animal Studies. In Peers C, Kumar P, Wyatt C, Gauda E, Nurse CA, Prabhakar N, (eds) Arterial Chemoreceptors in Physiology and Pathophysiology. Springer International Publishing: Cham. 2015.

[115] Niewinski P, Janczak D, Rucinski A, Tubek S, Engelman ZJ, Piesiak P, et al. Carotid body resection for sympathetic modulation in systolic heart failure: results from first-in-man study. European Journal of Heart Failure. 2017; 19: 391-400.

[116] Morgan BJ, Bates ML, Rio RD, Wang Z, Dopp JM. Oxidative stress augments chemoreflex sensitivity in rats exposed to chronic intermittent hypoxia. Respiratory Physiology \& Neurobiology. 2016; 234: 47-59.

[117] Roig E, Perez-Villa F, Morales M, Jiménez W, Orús J, Heras $\mathrm{M}$, et al. Clinical implications of increased plasma angiotensin II despite ACE inhibitor therapy in patients with congestive heart failure. European Heart Journal. 2000; 21: 53-57.

[118] van de Wal RMA, Plokker HWM, Lok DJA, Boomsma F, van der Horst FAL, van Veldhuisen DJ, et al. Determinants of increased angiotensin II levels in severe chronic heart failure patients despite ACE inhibition. International Journal of Cardiology. 2006; 106: 367-372.

[119] Li Y, Gao L, Zucker IH, Schultz HD. NADPH oxidase-derived superoxide anion mediates angiotensin II-enhanced carotid body chemoreceptor sensitivity in heart failure rabbits. Cardiovascular Research. 2007; 75: 546-554.

[120] Belardinelli R, Georgiou D, Cianci G, Purcaro A. 10-year exercise training in chronic heart failure: a randomized controlled trial. Journal of the American College of Cardiology. 2012; 60: $1521-1528$.

[121] Davies EJ, Moxham T, Rees K, Singh S, Coats AJS, Ebrahim $\mathrm{S}$, et al. Exercise training for systolic heart failure: Cochrane systematic review and meta-analysis. European Journal of Heart Failure. 2010; 12: 706-715.

[122] Sakai T, Yagishita A, Morise M, Sakama S, Ijichi T, Ayabe K, et al. Impact of exercise capacity on the long-term incidence of atrial arrhythmias in heart failure. Scientific Reports. 2021; 11: 18705 .

[123] Luo N, Merrill P, Parikh KS, Whellan DJ, Piña IL, Fiuzat M, et al. Exercise Training in Patients with Chronic Heart Failure and Atrial Fibrillation. Journal of the American College of Cardiology. 2017; 69: 1683-1691.

[124] Priori SG, Blomström-Lundqvist C, Mazzanti A, Blom N, Borggrefe M, Camm J, et al. 2015 ESC Guidelines for the management of patients with ventricular arrhythmias and the prevention of sudden cardiac death the Task Force for the Management of Patients with Ventricular Arrhythmias and the Prevention of Sudden Cardiac Death of the Europea. European Heart Journal. 2015; 36: 2793-2867.

[125] Zweerink A, van der Lingen ACJ, Handoko ML, van Rossum AC, Allaart CP. Chronotropic Incompetence in Chronic Heart Failure: A state-of-the-art review. Circulation: Heart Failure. 2018; 11: e004969.

[126] Pearson MJ, Smart NA. Exercise therapy and autonomic function in heart failure patients: a systematic review and metaanalysis. Heart Failure Reviews. 2018; 23: 91-108.

[127] Pügge C, Mediratta J, Marcus NJ, Schultz HD, Schiller AM, Zucker IH. Exercise training normalizes renal blood flow responses to acute hypoxia in experimental heart failure: role of the $\alpha 1$-adrenergic receptor. Journal of Applied Physiology. 2016; 120: 334-343.

[128] Gao L, Wang W, Liu D, Zucker IH. Exercise training normalizes sympathetic outflow by central antioxidant mechanisms in rabbits with pacing-induced chronic heart failure. Circulation. 
2007; 115: 3095-3102.

[129] Masson GS, Borges JP, da Silva PPS, da Nóbrega ACL, Tibiriçá E, Lessa MA. Effect of continuous and interval aerobic exercise training on baroreflex sensitivity in heart failure. Autonomic Neuroscience. 2016; 197: 9-13.

[130] Zheng H, Li Y, Cornish KG, Zucker IH, Patel KP. Exercise training improves endogenous nitric oxide mechanisms within the paraventricular nucleus in rats with heart failure. American Journal of Physiology. Heart and Circulatory Physiology. 2005; 288: H2332-H2341.

[131] Kleiber AC, Zheng H, Schultz HD, Peuler JD, Patel KP. Exercise training normalizes enhanced glutamate-mediated sympathetic activation from the PVN in heart failure. American Journal of Physiology. Regulatory, Integrative and Comparative Physiology. 2008; 294: R1863-R1872.

[132] Calegari L, Mozzaquattro BB, Rossato DD, Quagliotto E, Ferreira JB, Rasia-Filho $\mathrm{A}$, et al. Exercise training attenuates the pressor response evoked by peripheral chemoreflex in rats with heart failure. Canadian Journal of Physiology and Pharmacology. 2017; 94: 979-986.

[133] Ichige MHA, Santos CR, Jordão CP, Ceroni A, Negrão CE, Michelini LC. Exercise training preserves vagal preganglionic neurones and restores parasympathetic tonus in heart failure. The Journal of Physiology. 2016; 594: 6241-6254.

[134] Coats AJ, Adamopoulos S, Radaelli A, McCance A, Meyer TE, Bernardi L, et al. Controlled trial of physical training in chronic heart failure. Exercise performance, hemodynamics, ventilation, and autonomic function. Circulation. 1992; 85: 2119-2131.

[135] Adamopoulos S, Piepoli M, McCance A, Bernardi L, Rocadaelli A, Ormerod O, et al. Comparison of different methods for assessing sympathovagal balance in chronic congestive heart failure secondary to coronary artery disease. The American Journal of Cardiology. 1992; 70: 1576-1582.

[136] Radaelli A, Coats AJ, Leuzzi S, Piepoli M, Meyer TE, Calciati A, et al. Physical training enhances sympathetic and parasympathetic control of heart rate and peripheral vessels in chronic heart failure. Clinical Science. 1996; 91: 92-94.

[137] Malfatto G, Branzi G, Riva B, Sala L, Leonetti G, Facchini M. Recovery of cardiac autonomic responsiveness with lowintensity physical training in patients with chronic heart failure. European Journal of Heart Failure. 2002; 4: 159-166.

[138] Piotrowicz E, Buchner T, Piotrowski W, Piotrowicz R. Influence of home-based telemonitored Nordic walking training on autonomic nervous system balance in heart failure patients. Archives of Medical Science. 2015; 11: 1205-1212.

[139] Kiilavuori K, Toivonen L, Näveri H, Leinonen H. Reversal of autonomic derangements by physical training in chronic heart failure assessed by heart rate variability. European Heart Journal. 1995; 16: 490-495.

[140] Murad K, Brubaker PH, Fitzgerald DM, Morgan TM, Goff DC, Soliman EZ, et al. Exercise training improves heart rate variability in older patients with heart failure: a randomized, controlled, single-blinded trial. Congestive Heart Failure. 2012; 18: 192197.

[141] Ricca-Mallada R, Migliaro ER, Piskorski J, Guzik P. Exercise training slows down heart rate and improves deceleration and acceleration capacity in patients with heart failure. Journal of Electrocardiology. 2012; 45: 214-219.

[142] Roveda F, Middlekauff HR, Rondon MUPB, Reis SF, Souza $\mathrm{M}$, Nastari L, et al. The effects of exercise training on sympathetic neural activation in advanced heart failure: a randomized controlled trial. Journal of the American College of Cardiology. 2003; 42: 854-860.

[143] Tucker WJ, Beaudry RI, Liang Y, Clark AM, Tomczak CR, Nelson MD, et al. Meta-analysis of Exercise Training on Left Ventricular Ejection Fraction in Heart Failure with Reduced
Ejection Fraction: a 10-year Update. Progress in Cardiovascular Diseases. 2019; 62: 163-171.

[144] Tyni-Lenné R, Dencker K, Gordon A, Jansson E, Sylvén C. Comprehensive local muscle training increases aerobic working capacity and quality of life and decreases neurohormonal activation in patients with chronic heart failure. European Journal of Heart Failure. 2001; 3: 47-52.

[145] Tasoulis A, Papazachou O, Dimopoulos S, Gerovasili V, Karatzanos E, Kyprianou T, et al. Effects of interval exercise training on respiratory drive in patients with chronic heart failure. Respiratory Medicine. 2011; 104: 1557-1565.

[146] Laoutaris ID. Exercise intolerance and skeletal muscle metaboreflex activity in chronic heart failure: do we need to recruit more muscle in exercise training? European Journal of Preventive Cardiology. 2020; 27: 1858-1861.

[147] Antunes-Correa LM, Nobre TS, Groehs RV, Alves MJNN, Fernandes T, Couto GK, et al. Molecular basis for the improvement in muscle metaboreflex and mechanoreflex control in exercisetrained humans with chronic heart failure. American Journal of Physiology. Heart and Circulatory Physiology. 2014; 307: H1655-H1666.

[148] Piepoli M, Clark AL, Volterrani M, Adamopoulos S, Sleight P, Coats AJ. Contribution of muscle afferents to the hemodynamic, autonomic, and ventilatory responses to exercise in patients with chronic heart failure: effects of physical training. Circulation. 1996; 93: 940-952.

[149] Middlekauff HR, Nitzsche EU, Hoh CK, Hamilton MA, Fonarow GC, Hage A, et al. Exaggerated renal vasoconstriction during exercise in heart failure patients. Circulation. 2000; 101: 784-789.

[150] Notarius CF, Millar PJ, Keir DA, Murai H, Haruki N, O'Donnell E, et al. Training heart failure patients with reduced ejection fraction attenuates muscle sympathetic nerve activation during mild dynamic exercise. American Journal of Physiology-Regulatory, Integrative and Comparative Physiology. 2019; 317: R503-R512.

[151] Wang H, Li Y, Zucker IH, Wang W. Exercise training prevents skeletal muscle afferent sensitization in rats with chronic heart failure. American Journal of Physiology. Regulatory, Integrative and Comparative Physiology. 2012; 302: R1260-R1270.

[152] Wang H, Pan Y, Wang W, Gao L, Zimmerman MC, Zucker IH, et al. Exercise training prevents the exaggerated exercise pressor reflex in rats with chronic heart failure. Journal of Applied Physiology. 2010; 108: 1365-1375.

[153] Pietilä M, Malminiemi K, Vesalainen R, Jartti T, Teräs M, Någren $\mathrm{K}$, et al. Exercise training in chronic heart failure: beneficial effects on cardiac (11)C-hydroxyephedrine PET, autonomic nervous control, and ventricular repolarization. Journal of $\mathrm{Nu}$ clear Medicine. 2002; 43: 773-779.

[154] Gademan MGJ, van Exel HJ, van de Vooren H, Haest JCW, van Pelt J, van der Laarse A, et al. Exercise-resembling effects of periodic somatosensory stimulation in heart failure. International Journal of Cardiology. 2013; 168: 3327-3333.

[155] Iellamo F, Legramante JM, Massaro M, Raimondi G, Galante A. Effects of a residential exercise training on baroreflex sensitivity and heart rate variability in patients with coronary artery disease: a randomized, controlled study. Circulation. 2000; 102: 2588-2592.

[156] Laterza MC, de Matos LDNJ, Trombetta IC, Braga AMW, Roveda F, Alves MJNN, et al. Exercise training restores baroreflex sensitivity in never-treated hypertensive patients. Hypertension. 2007; 49: 1298-1306.

[157] Liu JL, Irvine S, Reid IA, Patel KP, Zucker IH. Chronic exercise reduces sympathetic nerve activity in rabbits with pacinginduced heart failure: a role for angiotensin II. Circulation. 2000; 102: 1854-1862. 
[158] Mousa TM, Liu D, Cornish KG, Zucker IH. Exercise training enhances baroreflex sensitivity by an angiotensin II-dependent mechanism in chronic heart failure. Journal of Applied Physiology. 2008; 104: 616-624.

[159] Liu J, Kulakofsky J, Zucker IH. Exercise training enhances baroreflex control of heart rate by a vagal mechanism in rabbits with heart failure. Journal of Applied Physiology. 2002; 92: 2403-2408.

[160] Rondon E, Brasileiro-Santos MS, Moreira ED, Rondon MUPB, Mattos KC, Coelho MA, et al. Exercise training improves aortic depressor nerve sensitivity in rats with ischemia-induced heart failure. American Journal of Physiology. Heart and Circulatory Physiology. 2006; 291: H2801-H2806.

[161] Johnson BD, Joyner MJ. Carotid body denervation: too soon to get breathless about heart failure? Journal of the American College of Cardiology. 2013; 62: 2431-2432.

[162] Li Y, Ding Y, Agnew C, Schultz HD. Exercise training improves peripheral chemoreflex function in heart failure rabbits. Journal of Applied Physiology. 2008; 105: 782-790.

[163] Marcus NJ, Pügge C, Mediratta J, Schiller AM, Del Rio R, Zucker $\mathrm{IH}$, et al. Exercise training attenuates chemoreflexmediated reductions of renal blood flow in heart failure. American Journal of Physiology. Heart and Circulatory Physiology. 2015; 309: H259-H266.

[164] Williamson JW, Fadel PJ, Mitchell JH. New insights into central cardiovascular control during exercise in humans: a central command update. Experimental Physiology. 2006; 91: 51-58.
[165] Fisher WJ, White MJ. Training-induced adaptations in the central command and peripheral reflex components of the pressor response to isometric exercise of the human triceps surae. The Journal of Physiology. 1999; 520 Pt 2: 621-628.

[166] Koba S, Gao Z, Xing J, Sinoway LI, Li J. Sympathetic responses to exercise in myocardial infarction rats: a role of central command. American Journal of Physiology. Heart and Circulatory Physiology. 2006; 291: H2735-H2742.

[167] Sarma S, Howden E, Lawley J, Samels M, Levine BD. Central Command and the Regulation of Exercise Heart Rate Response in Heart Failure with Preserved Ejection Fraction. Circulation. 2021; 143: 783-789.

[168] O'Connor GT, Buring JE, Yusuf S, Goldhaber SZ, Olmstead EM, Paffenbarger RS, et al. An overview of randomized trials of rehabilitation with exercise after myocardial infarction. Circulation. 1989; 80: 234-244.

[169] Kitzman DW, Whellan DJ, Duncan P, Pastva AM, Mentz RJ, Reeves GR, et al. Physical Rehabilitation for Older Patients Hospitalized for Heart Failure. New England Journal of Medicine. 2021; 385: 203-216.

[170] Sties SW, Andreato LV, de Carvalho T, Gonzáles AI, Angarten VG, Ulbrich AZ, et al. Influence of exercise on oxidative stress in patients with heart failure. Heart Failure Reviews. 2018; 23: 225-235.

[171] Vianna LC, Fisher JP. Reflex control of the cardiovascular system during exercise in disease. Current Opinion in Physiology. 2019; 10: 110-117. 